\title{
Carbon dioxide retrieval from OCO-2 satellite observations using the RemoTeC algorithm and validation with TCCON measurements
}

\author{
Lianghai $\mathrm{Wu}^{1}$, Otto Hasekamp ${ }^{1}$, Haili $\mathrm{Hu}^{1}$, Jochen Landgraf ${ }^{1}$, Andre Butz ${ }^{2,3}$, Joost aan de Brugh ${ }^{1}$, Ilse Aben ${ }^{1}$, \\ Dave F. Pollard ${ }^{4}$, David W. T. Griffith ${ }^{5}$, Dietrich G. Feist ${ }^{6}$, Dmitry Koshelev ${ }^{7}$, Frank Hase ${ }^{8}$, Geoffrey C. Toon ${ }^{9}$, \\ Hirofumi Ohyama ${ }^{10}$, Isamu Morino ${ }^{10}$, Justus Notholt ${ }^{11}$, Kei Shiomi ${ }^{12}$, Laura Iraci ${ }^{13}$, Matthias Schneider ${ }^{15}$, \\ Martine de Mazière $^{14}$, Ralf Sussmann ${ }^{15}$, Rigel Kivi ${ }^{16}$, Thorsten Warneke ${ }^{11}$, Tae-Young Goo ${ }^{17}$, and Yao Té ${ }^{7}$ \\ ${ }^{1}$ SRON Netherlands Institute for Space Research, Utrecht, the Netherlands \\ ${ }^{2}$ Institute of Atmospheric Physics, Deutsches Zentrum für Luft- und Raumfahrt e.V. (DLR), \\ Wessling-Oberpfaffenhofen, Germany \\ ${ }^{3}$ Meteorologisches Institut, Ludwig-Maximilians-Universität (LMU), Munich, Germany \\ ${ }^{4}$ National Institute of Water and Atmospheric Research (NIWA), Lauder, New Zealand \\ ${ }^{5}$ University of Wollongong, Wollongong, Australia \\ ${ }^{6}$ Max Planck Institute for Biogeochemistry, Jena, Germany \\ ${ }^{7}$ LERMA-IPSL, Sorbonne Universités, UPMC Univ Paris 06, CNRS, Observatoire de Paris, \\ PSL Research University, 75005, Paris, France \\ ${ }^{8}$ Karlsruhe Institute of Technology (KIT), IMK-ASF, Karlsruhe, Germany \\ ${ }^{9}$ Jet Propulsion Laboratory, California Institute of Technology, Pasadena, USA \\ ${ }^{10}$ National Institute for Environmental Studies (NIES), Tsukuba, Japan \\ ${ }^{11}$ University of Bremen, Bremen, Germany \\ ${ }^{12}$ Japan Aerospace Exploration Agency, Tsukuba, Japan \\ ${ }^{13}$ NASA Ames Research Center, Moffett Field, USA \\ ${ }^{14}$ Royal Belgian Institute for Space Aeronomy, Brussels, Belgium \\ ${ }^{15}$ Karlsruhe Institute of Technology (KIT), Institute of Meteorology and Climate Research (IMK-IFU), \\ Garmisch Partenkirchen, Germany \\ ${ }^{16}$ Finnish Meteorological Institute, Sodankylä, Finland \\ ${ }^{17}$ National Institute of Meteorological Research, Seoul, Republic of Korea
}

Correspondence: Lianghai Wu (l.wu@sron.nl)

Received: 21 November 2017 - Discussion started: 30 January 2018

Revised: 1 May 2018 - Accepted: 3 May 2018 - Published: 30 May 2018

\begin{abstract}
In this study we present the retrieval of the column-averaged dry air mole fraction of carbon dioxide $\left(X_{\mathrm{CO}_{2}}\right)$ from the Orbiting Carbon Observatory-2 (OCO-2) satellite observations using the RemoTeC algorithm, previously successfully applied to retrieval of greenhouse gas concentration from the Greenhouse Gases Observing Satellite (GOSAT). The $X_{\mathrm{CO}_{2}}$ product has been validated with collocated ground-based measurements from the Total Carbon Column Observing Network (TCCON) for almost 2 years of OCO-2 data from September 2014 to July 2016. We found that fitting an additive radiometric offset in all three spec-
\end{abstract}

tral bands of OCO-2 significantly improved the retrieval. Based on a small correlation of the $X_{\mathrm{CO}_{2}}$ error over land with goodness of fit, we applied an a posteriori bias correction to our OCO-2 retrievals. In overpass averaged results, $X_{\mathrm{CO}_{2}}$ retrievals have an $\mathrm{SD}$ of $\sim 1.30 \mathrm{ppm}$ and a station-tostation variability of $\sim 0.40 \mathrm{ppm}$ among collocated TCCON sites. The seasonal relative accuracy (SRA) has a value of $0.52 \mathrm{ppm}$. The validation shows relatively larger difference with TCCON over high-latitude areas and some specific regions like Japan. 


\section{Introduction}

Carbon dioxide $\left(\mathrm{CO}_{2}\right)$ concentration is rapidly increasing in the atmosphere due to fossil fuel combustion and deforestation (Prentice et al., 2001). This can lead to significant changes in climate (Cox et al., 2000; Caldeira and Wickett, 2003). Any mitigation strategy to reduce $\mathrm{CO}_{2}$ in the atmosphere requires a better understanding of the global carbon cycle, especially identifying carbon dioxide emissions from both natural and anthropogenic sources and sinks that absorb carbon dioxide. Our ability to quantify sources and sinks of $\mathrm{CO}_{2}$ is still insufficient due to the sparseness of current ground-based stations (Gurney et al., 2002; Patra et al., 2003; Houweling et al., 2004; Bösch et al., 2006; Baker et al., 2010).

To get a better understanding of the spatial and temporal pattern of sources and sinks of $\mathrm{CO}_{2}$, efforts have been made to retrieve $X_{\mathrm{CO}_{2}}$ from satellite observations. The thermal infrared observations of $\mathrm{CO}_{2}$ from instruments like the Atmospheric Infrared Sounder (AIRS), the Tropospheric Emission Spectrometer (TES) and the Infrared Atmospheric Sounding Interferometer (IASI) can provide $\mathrm{CO}_{2}$ measurements at altitudes between 5 and $15 \mathrm{~km}$ (Chédin et al., 2002; Engelen et al., 2004; Crevoisier et al., 2009). These measurements have a limited sensitivity to $\mathrm{CO}_{2}$ in the lower troposphere where $\mathrm{CO}_{2}$ sources and sinks are located. Satellite observations measuring in the shortwave infrared (SWIR) spectral range, however, are sensitive to $\mathrm{CO}_{2}$ down to the Earth's surface in the absence of clouds and so this spectral range is used to measure $X_{\mathrm{CO}_{2}}$ by several space missions. The SCanning Imaging Absorption spectroMeter for Atmospheric CHartographY (SCIAMACHY), operational between 2003 and 2012, is the pioneering instrument measuring $X_{\mathrm{CO}_{2}}$ from the SWIR spectra with sensitivity in the boundary layer (Buchwitz et al., 2005). Reuter et al. (2011) showed that accurate $X_{\mathrm{CO}_{2}}$ can be inferred from SCIAMACHY observations, taking atmospheric scattering processes into account in the retrieval. The Greenhouse Gases Observing Satellite (GOSAT), in orbit since January 2009 , is the first satellite primarily dedicated to monitor global atmospheric levels of $\mathrm{CO}_{2}$ and $\mathrm{CH}_{4}$ from space (Yokota et al., 2009). The $X_{\mathrm{CO}_{2}}$ derived from GOSAT has an accuracy on the order of a few tens of a percent (Butz et al., 2011; Guerlet et al., 2013b; Buchwitz et al., 2017a). $X_{\mathrm{CO}_{2}}$ retrievals with this level of accuracy can provide valuable information on the variation of $\mathrm{CO}_{2}$ (Rayner and O'Brien, 2001; Houweling et al., 2004; Guerlet et al., 2013a; Basu et al., 2014; Detmers et al., 2015). In July 2014, NASA's Orbiting Carbon Observatory-2 (OCO-2) satellite was successfully launched. OCO-2 is designed with three standard observational modes (nadir, glint and target) for accurate monitoring of the geographic distribution of carbon dioxide sources and sinks on a regional scale (Crisp et al., 2004). By taking advantage of the target mode where many observations are acquired over ground-based validation sites, the biases in the $X_{\mathrm{CO}_{2}}$ retrievals from OCO-2 measurements can be accurately evaluated. Furthermore, with a spatial sampling size of about $3 \mathrm{~km}^{2}$, the number of cloud-free $X_{\mathrm{CO}_{2}}$ OCO-2 observations exceeds significantly those of previous missions.

One of the main challenges of $X_{\mathrm{CO}_{2}}$ retrieval from SWIR satellite measurements is to characterize the light path through the atmosphere affected by atmospheric scattering and surface reflection (Aben et al., 2007). For this purpose, current missions include measurements in the nearinfrared (NIR) spectral range covering the $\mathrm{O}_{2}$ A absorption band. Measurements in the NIR and SWIR spectral bands allow for the simultaneous retrieval of carbon dioxide concentration with proper accounting of scattering properties introduced by aerosols or clouds. Several algorithms have been developed to retrieve $\mathrm{CO}_{2}$ from NIR and SWIR measurements from space, including the differential optical absorption spectroscopy (DOAS) retrieval method developed for the retrieval of SCIAMACHY (Buchwitz et al., 2000; Hönninger et al., 2004; Reuter et al., 2010), the algorithm developed at the National Institute for Environment Studies (NIES) for GOSAT observations (Yoshida et al., 2011), the Atmospheric $\mathrm{CO}_{2}$ Observations from Space (ACOS) retrieval algorithm developed for the OCO instrument and later applied to the GOSAT and OCO-2 observations (O'Dell et al., 2012; Crisp et al., 2012), the algorithm developed in the University of Leicester (UoL) (Boesch et al., 2011; Jung et al., 2016) and the RemoTeC algorithm developed by SRON Netherlands Institute for Space Research and Deutsches Zentrum für Luft- und Raumfahrt e.V. (DLR) (Hasekamp and Butz, 2008; Butz et al., 2011; Guerlet et al., 2013b).

The operational $X_{\mathrm{CO}_{2}}$ data product of the OCO-2 mission is derived with the ACOS algorithm and validated against ground-based measurements (Wunch et al., 2017) and a dataset is available for assessing regional-scale sources and sinks (Eldering et al., 2017). To enhance the reliability and confidence of the data product, however, analyzing the data with independent algorithms is essential. For example, in the greenhouse gas project of ESA's Climate Change Initiative (GHG-CCI) extensive comparisons were made between different $X_{\mathrm{CO}_{2}}$ retrieval algorithms, which showed similar results when comparing with Total Carbon Column Observing Network (TCCON) data. However, in other regions the differences were sometimes significantly larger (Dils et al., 2014). In this paper, we adapt and apply the $\mathrm{RemoTeC}$ retrieval algorithm, previously applied to the GOSAT measurements, to OCO-2 measurements obtained under nadir, glint and target modes and evaluate the $X_{\mathrm{CO}_{2}}$ retrieval data quality with collocated ground-based measurements from the TCCON (Wunch et al., 2011a). To screen out too challenging soundings (i.e., clouds, high aerosol loading, large spectral uncertainties) we optimized the a posteriori data filtering and developed an $X_{\mathrm{CO}_{2}}$ bias correction based on goodness of fit. We expect that application of RemoTeC to OCO-2 data will lead to a better understanding to 
the capabilities and limitations of the OCO-2 instrument and the operational level-2 data product. Furthermore, we see this work as a first step towards processing a larger data set with RemoTeC.

The paper is organized as follows: Sect. 2 describes the OCO-2 data and Sect. 3 introduces the RemoTeC full physics retrieval algorithm including cloud screening and adjustments specific to OCO-2 type of measurements. In Sect. 4, we evaluate our retrieval results using collocated TCCON measurements. Here, the effect of bias correction is also discussed. To further evaluate the RemoTeC/OCO-2 retrievals, Sect. 5 discusses the TCCON validation of $X_{\mathrm{CO}_{2}}$ data product from ACOS/OCO-2 and RemoTeC/GOSAT retrievals. Finally, Sect. 6 concludes the paper.

\section{Data}

The OCO-2 satellite provides measurements of sunlight backscattered by the Earth's surface and atmosphere in three channels including the molecular oxygen $\left(\mathrm{O}_{2}\right)$ A band (around $0.765 \mu \mathrm{m}, \mathrm{NIR}$ ), a weak $\mathrm{CO}_{2}$ band (around $1.61 \mu \mathrm{m}, \mathrm{SWIR}-1$ ) and a strong $\mathrm{CO}_{2}$ band (around $2.06 \mu \mathrm{m}$, SWIR-2) with a spectral resolution of $\sim 0.042, \sim 0.076$ and $\sim 0.097 \mathrm{~nm}$, respectively, defined as the full width at half maximum (FWHM) of the instrument spectral response. Each FWHM is over-sampled by a factor of 2 to 3 in the direction of dispersion. In each band, a linear polarizer is mounted in front of the imaging spectrometer and selects polarization vector parallel to the entrance slit. During operation, OCO-2 can collect observations with high signalto-noise ratios under nadir, glint and target modes and each sounding provides measurements in eight footprints adjacent to each other. The typical size of one footprint is around $1.3 \mathrm{~km} \times 2.25 \mathrm{~km}$ under the nadir observation mode and can be a bit larger for the other modes (Crisp et al., 2017).

In this study, we use version 7 OCO-2 data for the period September 2014 to July 2016. These data include observations obtained under nadir, glint and target observation modes. A few percent of the pixels of the OCO-2 detectors show performance anomalies (Crisp et al., 2017) and so we exclude the corresponding spectral samples using the mask information provided in the L1b files. Finally, only spectra are processed where at least half of the spectral samples pass this quality check.

For validation purpose, we focus on satellite observations that are collocated with measurements from the TCCON, which is a global network of ground-based instruments that can measure $X_{\mathrm{CO}_{2}}$ in the atmosphere (Wunch et al., 2011a). The $X_{\mathrm{CO}_{2}}$ measured by the TCCON has an uncertainty better than $0.25 \%$ ( 1 ppm) (Wunch et al., 2015). More information on TCCON sites including locations and operational status can be found at https://tccon-wiki.caltech.edu/. The collocation criteria between OCO-2 measurements and TCCON measurements include a geographical distance less than $5^{\circ}$ in both latitude and longitude and a time difference less than $2 \mathrm{~h}$. Due to the high spatial sampling of OCO-2 (24 spectra per second over the swath), there are generally more than 150 cloud-screened spectra available for each collocated TCCON measurement. In this case, we use a maximum of 150 nadir or glint spectra, which are spatially closest to TCCON site, while for target observations we select those obtained with a viewing zenith angle smaller than $30^{\circ}$. This viewing zenith angle restriction has only been applied for target observations for time efficiency.

In addition to the OCO-2 spectra, the retrieval algorithm requires information on vertical profiles of pressure, temperature, humidity and surface wind speed, which are interpolated from the ECMWF (European Centre for MediumRange Weather Forecasts) high-resolution 10-day forecast analysis data on a $0.125^{\circ} \times 0.125^{\circ}$ latitude $\times$ longitude grid . The interpolation is performed with linear interpolation in time and nearest neighbor in space. The surface elevation information of the OCO-2 footprint is extracted from the $90 \mathrm{~m}$ digital elevation data of NASA's Shuttle Radar Topography Mission (SRTM) (Farr et al., 2007). For each OCO-2 footprint, all SRTM grid points within the boundary are collected to get mean surface elevation and its variation. We extrapolate the lowest ECMWF pressure point to the surface elevation provided by the SRTM data using the hypsometric equation. To provide the algorithm initial guess of the $\mathrm{CO}_{2}$ vertical concentration profiles and the $\mathrm{CH}_{4}$ total column at each location, we use data from CarbonTracker and TM5 model for the year 2013 and 2010 (Peters et al., 2007; Houweling et al., 2014), respectively. The high-resolution solar irradiance data by Dr. R. Kurucz (http://kurucz.harvard.edu/sun/ irradiance2008/) is used as reference solar spectrum in the forward radiative transfer model.

\section{Method}

The RemoTeC algorithm has been described in detail by Hasekamp and Butz (2008) and Butz et al. (2009, 2010) and has been applied for $\mathrm{CO}_{2}$ and $\mathrm{CH}_{4}$ retrievals from GOSAT measurements (Butz et al., 2011; Schepers et al., 2012; Guerlet et al., 2013b). For OCO-2 application, the two most important algorithmic modifications are (1) a vector radiative transfer model (LINTRAN V2) employed in the retrieval scheme (Hasekamp and Landgraf, 2002, 2005a; Schepers et al., 2014) and (2) aerosol scattering effects taken into account for ocean glint retrievals.

In the following, we assume that the OCO-2 radiance measurements $\boldsymbol{y}$, comprising of measurements in all three bands, can be described by a forward radiative transfer model $\boldsymbol{F}$ via

$\boldsymbol{y}=\boldsymbol{F}(\boldsymbol{x}, \boldsymbol{b})+\boldsymbol{e}$.

Here, $\boldsymbol{x}$ is the state vector containing all parameters to be retrieved and $\boldsymbol{b}$ includes a set of auxiliary input parameters. The error term $\boldsymbol{e}$ contains uncertainties in both instrument and for- 
ward model. To infer $X_{\mathrm{CO}_{2}}$, RemoTeC resolves Eq. (1) with respect to the state vector $\boldsymbol{x}$.

The OCO-2 instrument measures the backscattered sunlight in a single polarization direction, and so the forward model for spectral sampling $i$ reads

$F_{i}(\boldsymbol{x}, \boldsymbol{b})=m_{11} I_{i}+m_{12} Q_{i}+m_{13} U_{i}$,

where $I_{i}, Q_{i}$ and $U_{i}$ are the first three Stokes parameters of a line-by-line top of the model atmosphere spectrum convolved with the OCO-2 instrument spectral response function. The elements of the Mueller matrix $m_{11}, m_{12}$ and $m_{13}$ describe the instrument polarization sensitivity depending on the illumination and observing geometries of the OCO-2 instrument. For the simulation of the line-by-line spectra, we employ the LINTRAN vector radiative transfer model (Hasekamp and Landgraf, 2002, 2005a; Schepers et al., 2014). To simulate efficiently the spectral dependence of the Stokes parameter $I, Q$ and $U$, defined at the top of the model atmosphere, the multiple scattering calculations are performed following the $k$-binning approach of Hasekamp and Butz (2008) while the single scattering is calculated line by line. In the algorithm, the model atmosphere is divided into 36 sub-layers for the radiative transfer calculation and further divided into 72 sub-layers for absorption crosssection calculation, which is highly dependent on temperature and pressure.

Since the measurement $\boldsymbol{y}$ does not contain sufficient information to retrieve all elements of state vector $\boldsymbol{x}$, the algorithm employs a Phillips-Tikhonov regularization scheme to solve the minimization problem iteratively (Phillips, 1962; Tikhonov, 1963; Hasekamp and Landgraf, 2005b):

$\hat{\boldsymbol{x}}=\min _{\boldsymbol{x}}\left(\left\|\boldsymbol{S}_{y}^{-\frac{1}{2}}(\boldsymbol{F}(\boldsymbol{x})-\boldsymbol{y})\right\|^{2}+\gamma\left\|\boldsymbol{W}\left(\boldsymbol{x}-\boldsymbol{x}_{a}\right)\right\|^{2}\right)$,

where $S_{y}$ is the diagonal measurement error covariance matrix that contains the measurement error estimates of OCO-2, $\boldsymbol{x}_{a}$ is a prior state vector, $\gamma$ is the regularization parameter and $\boldsymbol{W}$ is the weighting matrix making the side constraint dimensionless. The value for $\gamma$ is fixed such that the degree of freedom for signal (DFS) for the carbon dioxide profile is in the range 1.0-1.5. To avoid diverging retrievals, following a Gauss-Newton scheme (Rodgers, 2000) a filter factor $\left(\Lambda=\frac{1}{1+\xi}, \xi \geq 0\right)$ is also introduced to limit the update of the state vector per iteration step. More details on this aspect of the RemoTeC implementation can be found in Butz et al. (2012). The retrieval is considered successful when the following conditions are all met: (1) the update of the state vector $\boldsymbol{x}$ becomes smaller than its theoretical uncertainty; (2) the step-size parameter $\xi$ has reached 0 ; and (3) the state vector elements have never reached unrealistic values during the iteration.

The forward model assumes the land surface reflection to be Lambertian, whereas ocean surface reflection is mod- eled using a wind-speed-dependent Cox-and-Munk reflection model (Cox and Munk, 1954) with a wavelengthdependent Lambertian term added to it. Oxygen absorption lines in the A band are calculated by a spectroscopic model that accounts for line mixing and collision-induced absorption processes (Tran and Hartmann, 2008). Absorption lines of $\mathrm{CO}_{2}$ are modeled accordingly to the HITRAN 2008 spectroscopic database, by taking line mixing into account (Rothman et al., 2009; Lamouroux et al., 2010). HITRAN 2008 is also used to model absorption lines of $\mathrm{CH}_{4}$ and $\mathrm{H}_{2} \mathrm{O}$ assuming a Voigt lineshape model. In the retrieval, we treat aerosol as spherical particles with a constant refractive index (1.400-0.003i) over the whole OCO-2 spectral range. The aerosol size distribution is described by a power-law function $\left(n(r) \propto r^{-\alpha_{s}}\right)$ with size parameter $\alpha_{s}$ while the aerosol height profile is assumed to be Gaussian with a central height parameter $z_{s}$ and a fixed geometric width of $2 \mathrm{~km}$. Based on this aerosol model, we calculate the optical properties of aerosol particles using the tabulated kernels of Dubovik et al. (2006).

In the retrieval, the state vector $\boldsymbol{x}$ includes the 12-layer profile of $\mathrm{CO}_{2}$ sub-column number densities along with total column number densities of interfering absorbers $\mathrm{CH}_{4}$ and $\mathrm{H}_{2} \mathrm{O}$ and surface parameters, including a second-order spectral dependence of the Lambertian surface albedo in all OCO- 2 bands. Moreover, $\boldsymbol{x}$ contains the aerosol size parameter $\alpha_{s}$ of the power-law distribution, the total column density of aerosol particles and the central height parameter $z_{s}$ of the Gaussian height distribution. Finally, in all three bands we infer an intensity offset, a first-order spectral shift of the Earth radiance spectrum and a spectral shift of the solar reference spectrum. To initialize the retrieval, we choose an aerosol total column, which corresponds to an aerosol optical depths of 0.1 in the NIR spectral band, a size parameter $\alpha_{s}=4.5$ and an aerosol layer height $z_{s}=3000 \mathrm{~m}$. Table 1 lists the state vector elements and prior values, if applicable, considered in the retrieval. After convergence, the spectral fit residuals are generally less than $1.0 \%$ with a typical reduced chi squared distribution of 3.0.

Since clouds are not considered in RemoTeC, a cloud screening of the OCO-2 data is required before performing full physical retrieval. For this purpose, we implemented a fast non-scattering retrieval as part of the RemoTeC and compare columns of $\mathrm{O}_{2}, \mathrm{CO}_{2}$ and $\mathrm{H}_{2} \mathrm{O}$, which are retrieved independently from the NIR, SWIR-1 and SWIR2 bands of OCO-2, respectively. When neglecting cloud and aerosol scattering a large deviation can be introduced between $\mathrm{CO}_{2}$ and $\mathrm{H}_{2} \mathrm{O}$ columns retrieved from SWIR-1 and SWIR-2 bands due to different light path sensitivity. Similarly, for scenes with larger photon path-length modification, the retrieved $\mathrm{O}_{2}$ column will deviate more from the $\mathrm{O}_{2}$ column provided by the ECMWF. Cloud filtering is performed by applying the following criteria: $0.885<$ $\mathrm{O}_{2}^{\text {ret }} / \mathrm{O}_{2}^{\text {ecmwf }}<1.020,0.990<\mathrm{CO}_{2}^{\text {swir1 }} / \mathrm{CO}_{2}^{\text {swir2 }}<1.035$ and $0.950<\mathrm{H}_{2} \mathrm{O}^{\text {swir1 }} / \mathrm{H}_{2} \mathrm{O}^{\text {swir2 }}<1.060$. Here, around $30 \%$ of 
Table 1. State vector elements and their a priori values considered in the retrieval.

\begin{tabular}{|c|c|c|}
\hline State vector element & A priori & Unit \\
\hline Twelve $\mathrm{CO}_{2}$ sub-columns & CarbonTracker 2013 & molec $\mathrm{cm}^{-2}$ \\
\hline $\mathrm{H}_{2} \mathrm{O}$ total column & ECMWF & molec $\mathrm{cm}^{-2}$ \\
\hline $\mathrm{CH}_{4}$ total columns & TM5 & molec $\mathrm{cm}^{-2}$ \\
\hline Three parameters of the Lambertian surface albedo, NIR & Estimated from mean radiance & - \\
\hline Addictive intensity offset, NIR & 0.0 & $\mathrm{Ph} \mathrm{s}^{-1} \mathrm{~m}^{-2} \mathrm{sr}^{-1} \mu \mathrm{m}^{-1}$ \\
\hline Zero-order spectral shift, NIR & 0.0 & - \\
\hline Solar reference spectral shift, NIR & 0.0 & - \\
\hline Three parameters of the Lambertian surface albedo, SWIR-1 & Estimated from mean radiance & - \\
\hline Addictive intensity offset, SWIR-1 & 0.0 & $\mathrm{Ph} \mathrm{s}^{-1} \mathrm{~m}^{-2} \mathrm{sr}^{-1} \mu \mathrm{m}^{-1}$ \\
\hline Zero-order spectral shift, SWIR-1 & 0.0 & - \\
\hline Solar reference spectral shift, SWIR-1 & 0.0 & - \\
\hline Three parameters of the Lambertian surface albedo, SWIR-2 & Estimated from mean radiance & - \\
\hline Addictive intensity offset, SWIR-2 & 0.0 & $\mathrm{Ph} \mathrm{s}^{-1} \mathrm{~m}^{-2} \mathrm{sr}^{-1} \mu \mathrm{m}^{-1}$ \\
\hline Zero-order spectral shift, SWIR-2 & 0.0 & - \\
\hline Solar reference spectral shift, SWIR-2 & 0.0 & - \\
\hline Aerosol size parameter & 4.5 & $\mu \mathrm{m}$ \\
\hline Aerosol column & $6.84 \times 10^{12}$ & $m^{-2}$ \\
\hline Aerosol layer central height & 3000 & $\mathrm{~m}$ \\
\hline
\end{tabular}

total soundings are identified as cloud-free cases by the cloud screening. If estimated separately, the percentage of clear soundings are 24,28 and $34 \%$ for target, land and ocean glint observations, respectively. For now, we mainly use those ratios as a option to filter cloud-contaminated cases for the full physical retrieval. Apart from cloud screening, observations with solar zenith angle $>70^{\circ}$ and large surface roughness (SD of surface elevation $>75 \mathrm{~m}$ ) are also excluded before performing the operational retrievals.

\section{Validation with the TCCON}

In this section, we evaluate the $X_{\mathrm{CO}_{2}}$ retrieved from OCO-2 measurements using the RemoTeC algorithm against groundbased measurements at a comprehensive set of TCCON stations. Figure 1 shows an example of validation between RemoTeC/OCO-2 retrievals and TCCON measurements over Lamont and Darwin stations. Here, we can see that RemoTeC/OCO-2 retrievals can capture well the seasonal $X_{\mathrm{CO}_{2}}$ variation features of both the Northern Hemisphere and Southern Hemisphere. To better evaluate our retrieval quality, we use the bias $(b)$ as the mean difference between collocated TCCON and OCO- 2 retrievals, the sounding precision $(\sigma)$ as the SD of the difference and the stationto-station variability $\left(\sigma_{\mathrm{s}}\right)$ as the SD of the biases for different TCCON stations. Here, retrievals over land and ocean are evaluated separately. The separation is due to the fact that land and ocean surface reflections are modeled differently. Land retrievals include observations obtained under nadir and glint modes and ocean retrievals only include observations under glint mode. Target mode observations, mostly performed coincidentally around TCCON sites over land, are evaluated separately. Moreover, the SD over all seasonal bias results, known as seasonal relative accuracy (SRA) as introduced by Dils et al. (2014), is also derived for all three types of retrievals. The SRA value is a good indicator of the variability of the bias in both space and time. In the following validation, we assume that TCCON measurements themselves are consistent over all stations with a station-tostation variability of zero. However, as discussed by Kulawik et al. (2016) and Buchwitz et al. (2017b), individual stations have a year-to-year variability of $\sim 0.3 \mathrm{ppm}$ and the overall TCCON $X_{\mathrm{CO}_{2}}$ uncertainty is around $0.4 \mathrm{ppm}$ (1 sigma). Although some limitations may exist, TCCON measurements are the most appropriate validation data product for satellite observations. Here, we exclude stations located either close to source region such as Caltech or at very high latitude such as Eureka. Land retrievals obtained over Réunion, located within areas with significant topography and an active volcano, will also not be used for validation.

\subsection{Filters and bias correction}

We first compare our retrieval results with collocated TCCON data to establish a set of values for the filters shown in Table 2 to screen out retrievals with larger uncertainties. In our retrieval, around 83,81 and $72 \%$ of cloud-free cases successfully converge and, after applying the filters in Table 2, 66, 50 and $47 \%$ of retrievals remain with good quality in cloud-screened target, land and ocean types of measurements, respectively. The overall L2-processed throughput is around $15 \%$. When estimated separately, the percentages are 

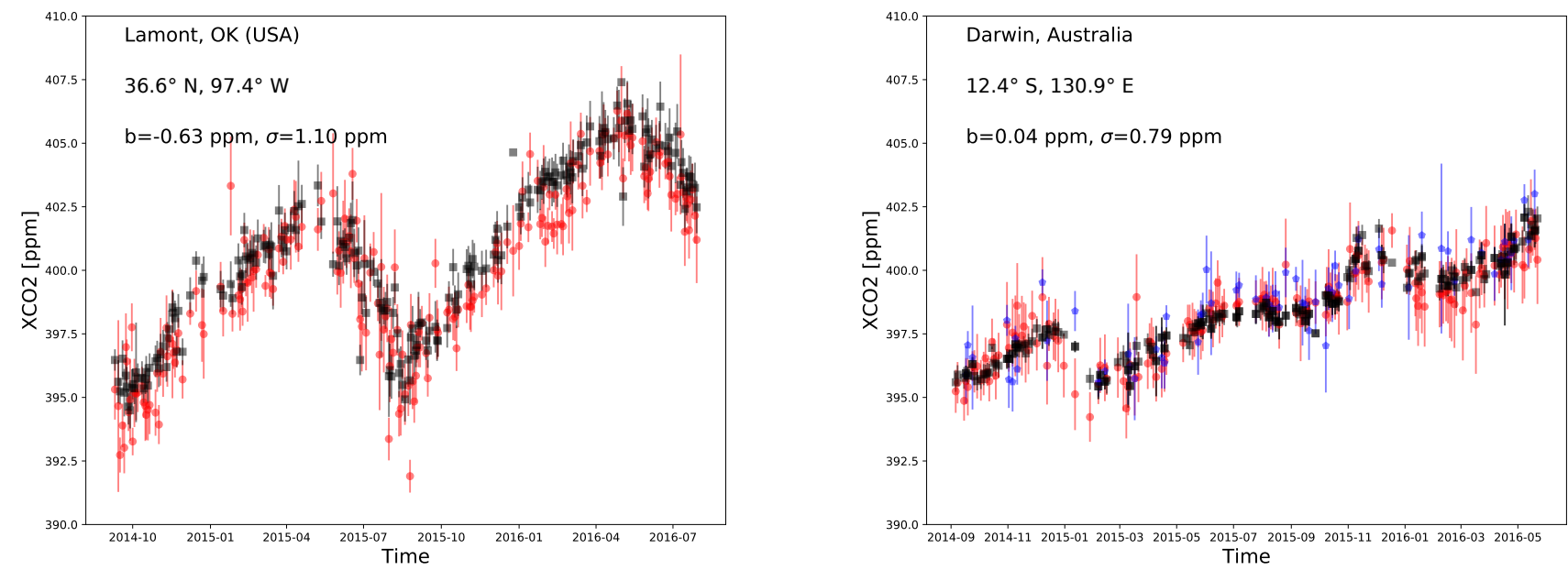

Figure 1. Time variation of $X_{\mathrm{CO}_{2}}$ retrievals from OCO-2 observations over land (red dots) and ocean (blue pentagon) and collocated TCCON measurements (black square) for Lamont and Darwin stations. SD of individual TCCON measurement and satellite retrievals are presented with the length of bar. In each subplot, the mean bias $(b)$ and SD $(\sigma)$ of the difference between RemoTeC/OCO-2 retrievals and TCCON measurements and site location in latitude and longitude are included. The shown results here are bias-corrected data.
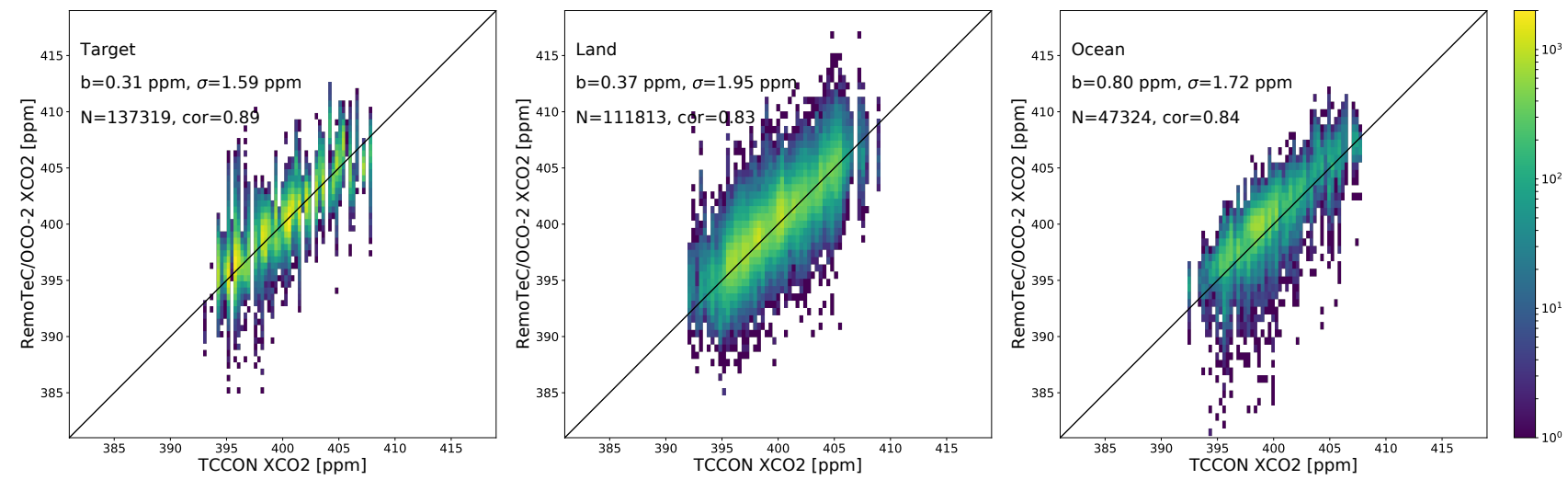

Figure 2. Validation of individual $X_{\mathrm{CO}_{2}}$ retrieved from OCO-2 measurements with collocated TCCON data before bias correction. Here, target retrievals are separated intentionally from land retrievals results, which thus include only measurements obtained under nadir and glint modes. Ocean retrievals only include glint mode observations over ocean. For retrievals collocated with multiple TCCON stations, we use data from the closest station. The bias (b), sounding precision $(\sigma)$, number of points $(N)$, the Pearson correlation coefficient (cor) and one-to-one line are included. Different colors represent the frequency of point occurrence.

$15.8,14.0$ and $16.0 \%$ for target, land and ocean soundings, respectively.

Similar to the work of Butz et al. (2011) and Guerlet et al. (2013b), we apply filters to reject retrievals with bad quality of fit $\left(\chi^{2}>7.0, \chi_{1 \mathrm{st}}^{2}>7.0\right.$ or not converged with number of iterations $>30)$, with high aerosol loading $\left(\tau_{0.765}>\right.$ 0.35), with extreme aerosol parameters $\left(\alpha_{s}<3.5, \alpha_{s}>8.0\right.$ or aerosol ratio parameter $>300 \mathrm{~m}$ ), or with surface types like snow or ice (blended albedo $>0.9$ ). Here, the reduced $\chi^{2}$ is defined as

$1 / N \sum_{i=1}^{N}\left(\frac{y(i)-F(i)}{\delta_{i}}\right)^{2}$,

in which $N$ is the number of measurements minus the DFS, $y(i)$ is the OCO-2 measurement, $F(i)$ is the simulated result and $\delta_{i}$ is the uncertainty of the OCO-2 measurements. In OCO-2 retrievals, intensity offset parameters are fitted for all the three spectral windows and we use the ratio between retrieved intensity offset and mean spectral radiance to filter out soundings with larger spectral uncertainties. Here, target retrievals have the same filter settings as land retrievals. 
Table 2. Settings of the filters used for excluding RemoTeC/OCO-2 $X_{\mathrm{CO}_{2}}$ retrievals. The sign "-" indicates using the same option as in land retrievals.

\begin{tabular}{|c|c|c|c|}
\hline \multirow[t]{2}{*}{ Parameter } & \multirow[t]{2}{*}{ Definition } & \multicolumn{2}{|c|}{ Allowed range } \\
\hline & & Land & Ocean \\
\hline sza & Solar zenith angle & val $\leq 70^{\circ}$ & - \\
\hline vza & Viewing zenith angle & val $\leq 45^{\circ}$ & - \\
\hline iter & Number of retrieval iterations & val $\leq 30$ & - \\
\hline dfs & Degrees of freedom for signal for $\mathrm{CO}_{2}$ & val $\geq 1.0$ & - \\
\hline$\chi^{2}$ & Overall goodness of fit & val $\leq 7.0$ & - \\
\hline$\chi_{1 \mathrm{st}}^{2}$ & Goodness of fit in $\mathrm{O}_{2} \mathrm{~A}$ band & val $\leq 7.0$ & - \\
\hline Blended albedo* & $2.4 \times$ albedo_NIR $-1.13 \times$ albedo_SWIR-2 & val $\leq 0.9$ & None \\
\hline $\mathrm{alb}_{2}$ & Added Lambertian term in SWIR-2 band & None & val $\leq 0.065$ \\
\hline sev & Surface elevation variation & $\mathrm{val} \leq 75 \mathrm{~m}$ & None \\
\hline$\alpha_{s}$ & Aerosol size parameter & $3.5 \leq$ val $\leq 8.0$ & $3.5 \leq$ val $\leq 5.5$ \\
\hline$\tau_{0.765}$ & Aerosol optical depth in $\mathrm{O}_{2} \mathrm{~A}$ band & val $\leq 0.35$ & val $\leq 0.55$ \\
\hline Aerosol ratio parameter & $\tau_{0.765}{ }^{*} z_{s} / \alpha_{s}, z_{s}$ is aerosol layer height & val $\leq 300 \mathrm{~m}$ & - \\
\hline Xerr & Retrieval uncertainty for $X_{\mathrm{CO}_{2}}$ & val $\leq 2.0 \mathrm{ppm}$ & - \\
\hline $\mathrm{IOFF}_{1}$ & Fitted intensity offset ratio in NIR band & $-0.005 \leq$ val $\leq 0.015$ & - \\
\hline $\mathrm{IOFF}_{2}$ & Fitted intensity offset ratio in SWIR-1 band & $-0.001 \leq$ val $\leq 0.015$ & - \\
\hline $\mathrm{IOFF}_{3}$ & Fitted intensity offset ratio in SWIR-2 band & $-0.001 \leq$ val $\leq 0.015$ & - \\
\hline
\end{tabular}

* The blended albedo filter was first introduced in Wunch et al. (2011b).

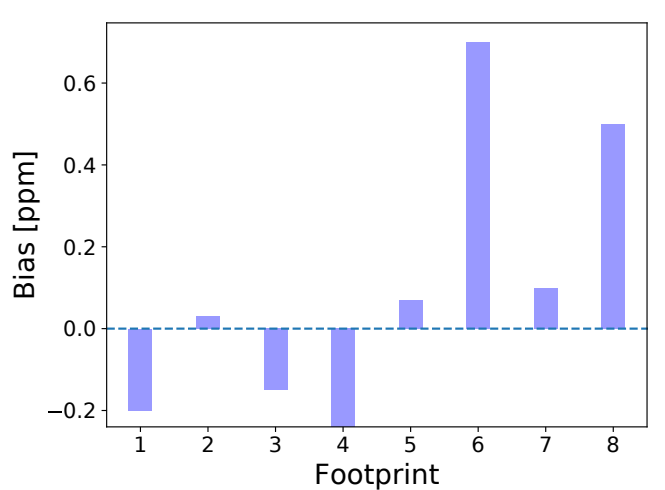

Figure 3. Estimated swath-dependent biases using Target mode observations.

Ocean glint measurements require different filter settings because of their different sensitivity due to unique viewing geometry and different surface properties. Moreover, in the measured radiance of ocean glint measurements, the contribution from aerosol scattering is negligible when compared with that from ocean surface reflection. As a consequence, the measured radiances are mainly sensitive to ocean reflection and aerosol layer extinction properties. Aerosol filter settings used here are different from land retrievals due to the limitation of aerosol information and aerosol parameters like particle size and layer height usually retain their prior values.

When comparing individual retrieval results with collocated TCCON measurements, we look for possible corrections of errors with instrumental, geophysical, meteorologi- cal and retrieved parameters. This correction should be valid for each single sounding and thus evaluated with individual results. In this paper, a positive bias means $X_{\mathrm{CO}_{2}}$ is overestimated by the RemoTeC/OCO- 2 retrievals. Figure 2 shows that only a small overall bias of $0.31,0.37$ and $0.70 \mathrm{ppm}$ exist in the RemoTeC/OCO-2 retrievals for target, land and ocean types of retrievals, respectively. Here, the dependency of difference between OCO-2 and TCCON with collocation distance and surface pressure is negligible. However, if we look at retrievals from eight individual footprints within a swath separately, the $X_{\mathrm{CO}_{2}}$ retrievals show statistically significant differences on overall biases ranging from -0.25 to $0.65 \mathrm{ppm}$ with an SD of $0.3 \mathrm{ppm}$. These biases arise from uncertainties in the $\mathrm{L} 1$ processing depending on the viewing direction in across-flight direction and have to be removed before performing an overall bias correction. To identify the footprintdependent biases, we use target mode observations when all eight footprints in one sounding frame converged, which provides around 7000 available retrievals per footprint. By using a large amount of target observations we can reduce the uncertainties in the footprint-to-footprint bias estimation. Here, we assume a constant $X_{\mathrm{CO}_{2}}$ field in the across-track direction. The estimated swath-dependent biases, as shown in Fig. 3, are directly subtracted from each footprint.

After removing the swath-dependent biases, a bias dependence on the $\chi^{2}$ in SWIR-1 band is found for RemoTeC/OCO-2 retrievals over land. As shown in Fig. 4, a typical $\chi^{2}$ in SWIR-1 band is around 2.0 and the correlation coefficient is 0.20 . Here, $\chi^{2}$ in SWIR-1 and SWIR-2 bands are highly correlated with corresponding retrieved surface albedos. A possible explanation for the correlation be- 

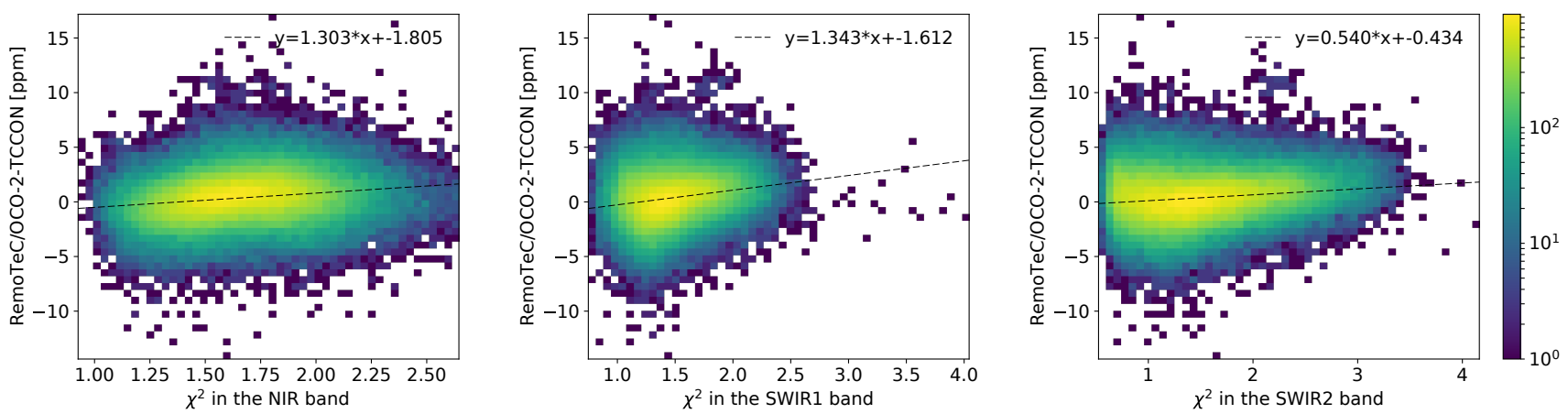

Figure 4. Error on $X_{\mathrm{CO}_{2}}$ retrievals as a function of the goodness of fit in the NIR, SWIR-1 and SWIR-2 bands. Different colors represent the frequency of point occurrence. The dashed line is a linear regression fit to the data.

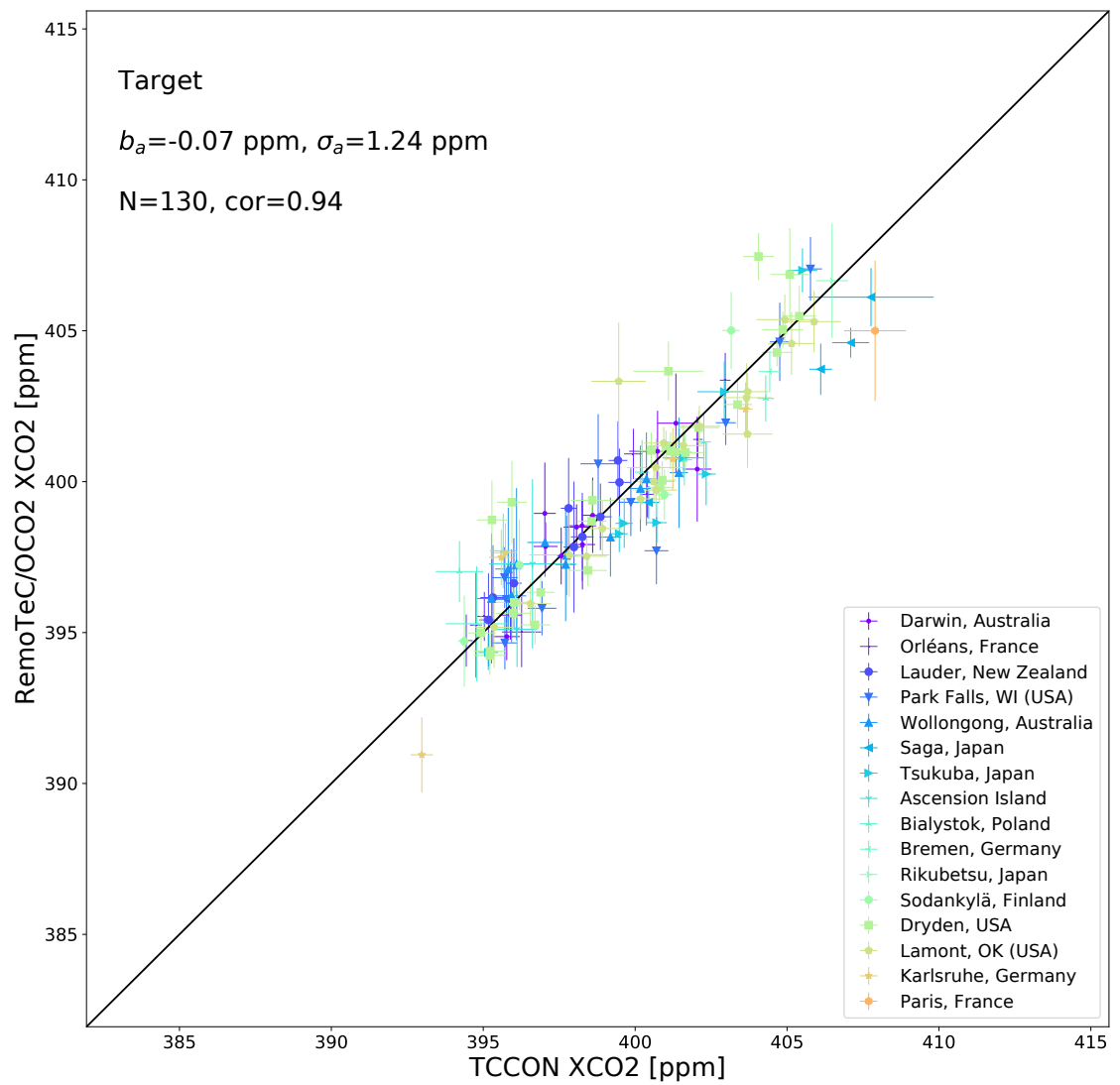

Figure 5. Validation of averaged $X_{\mathrm{CO}_{2}}$ retrieved from OCO-2 target measurements with collocated TCCON data. The retrieval results shown here are overpass averages of single soundings per station within $2 \mathrm{~h}$. The SD of individual TCCON data and that of RemoTeC/OCO-2 retrievals are presented with error bars. The bias $\left(b_{\mathrm{a}}\right), \mathrm{SD}\left(\sigma_{\mathrm{a}}\right)$, number of points $(N)$, the Pearson correlation coefficient (cor) and one-to-one line are included.

tween bias and $\chi^{2}$ is that $\chi^{2}$ correlates with surface brightness. For bright surfaces, the noise becomes small and some "constant" fit residuals show up. This "constant" fit residuals can be attributed to many factors like spectroscopic errors, inconsistent aerosol assumptions and instrument or algorithm uncertainties. Here, we correct this bias by

$$
\mathrm{XCO}_{2}^{\text {corr }}=\mathrm{XCO}_{2}\left(d+k \cdot \chi_{\text {swirl }}^{2}\right) \text {, }
$$

where the coefficients $k=-0.001261$ and $d=1.001938$ are derived with a linear regression fit through the difference between individual retrievals and TCCON measurements. This 


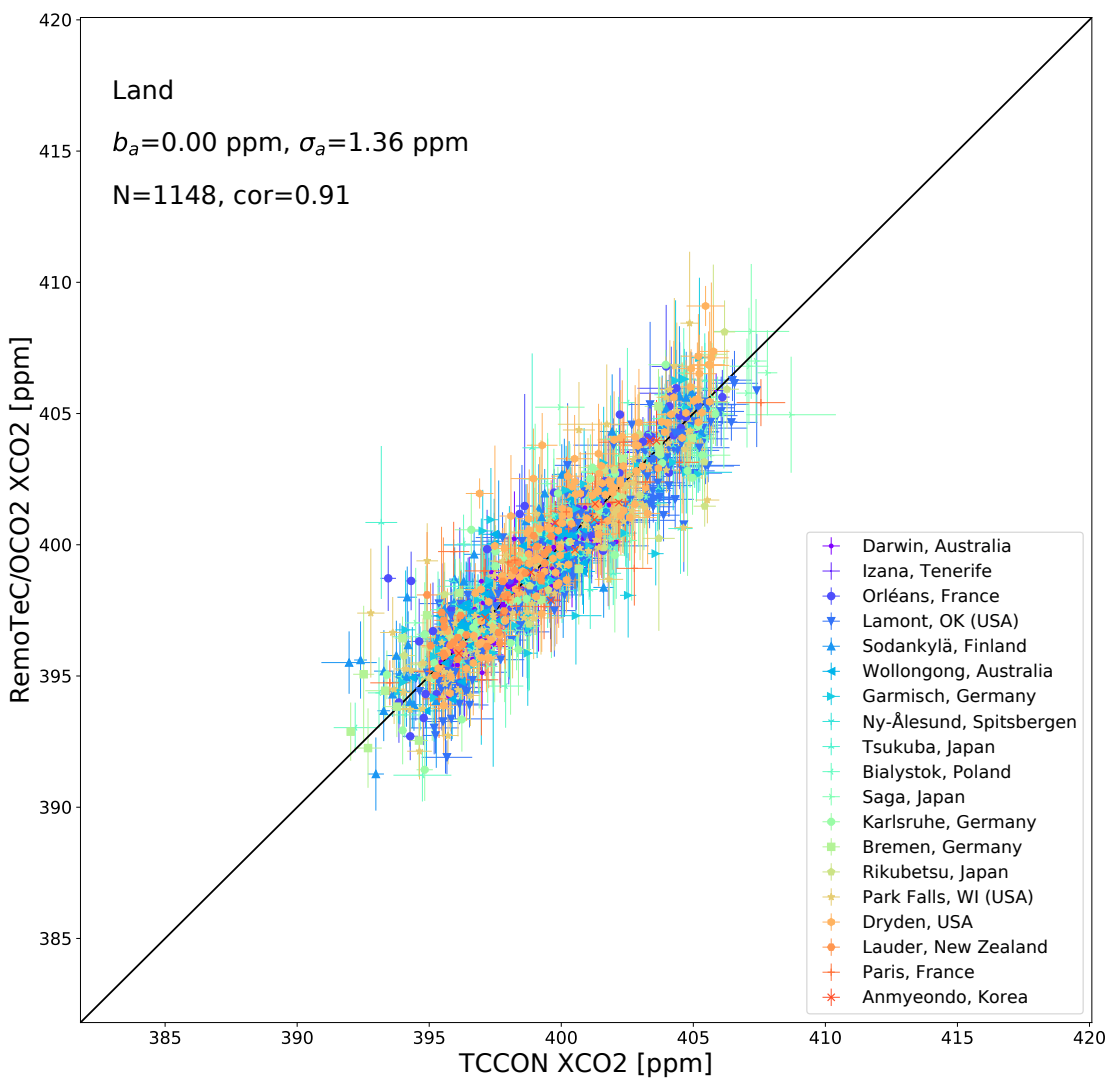

Figure 6. Same as Fig. 5, but for OCO-2 land type measurements obtained under nadir and glint modes.

correction reduces the error correlation with most parameters in Table 2 such as overall $\chi^{2}$, surface albedo in the NIR band (albedo_NIR), solar zenith angle and DFS, even though these parameters are not used in the bias correction and the remaining correlations with related parameters are generally less or around 0.15. After applying this bias correction the swath-dependent biases remains low around $-0.1 \mathrm{ppm}$ with an SD of $0.01 \mathrm{ppm}$. Similar improvement can be achieved by using $\chi^{2}$ in SWIR-2 band in the bias correction.

For ocean glint retrievals, we only subtract the swathdependent bias and a constant bias of $0.65 \mathrm{ppm}$ from the $X_{\mathrm{CO}_{2}}$ results. The constant bias is obtained by validating retrieval results with collocated TCCON measurements from sites as listed in Fig. 7. The $X_{\mathrm{CO}_{2}}$ swath-dependent bias for ocean glint observations is very similar to the one of $X_{\mathrm{CO}_{2}}$ target observations and so the same correction is applied.

Overall, with the bias correction in Eq. (4) the sounding precisions $\sigma$ are slightly improved by $\sim 0.1 \mathrm{ppm}$ for land retrievals in Fig. 2. The land and ocean bias corrections are developed for reducing globally relevant biases and thus geographically related or time-dependent biases may remain in the results and need further investigation.

\subsection{TCCON validation}

For a detailed validation of the bias-corrected $X_{\mathrm{CO}_{2}}$ product, we will evaluate the $X_{\mathrm{CO}_{2}}$ retrieved from OCO-2 target, land and ocean measurements using the $\mathrm{RemoTeC}$ algorithm for different TCCON stations separately. The average of the retrieved $X_{\mathrm{CO}_{2}}$ is compared with the corresponding TCCON average values. We exclude cases where less than five individual data points are available within $2 \mathrm{~h}$ in either OCO-2 retrievals or TCCON data. To evaluate the retrieval quality, we take into account the bias $\left(b_{\mathrm{a}}\right), \operatorname{SD}\left(\sigma_{\mathrm{a}}\right)$, stationto-station variability $\left(\sigma_{\mathrm{s}}\right)$ and SRA against TCCON measurements station by station. Here, the station-to-station variability is an important evaluation parameter known as a measure of regional-scale accuracy, which is most important for estimating $\mathrm{CO}_{2}$ surface-to-atmosphere fluxes on regional scales. The SRA value further indicates the potential bias variation in both space and time. Moreover, we study the effect of the bias correction by analyzing the retrieval performance station by station.

Figures 5, 6 and 7 show the overall comparisons between RemoTeC/OCO-2 retrievals after bias correction and TC$\mathrm{CON}$ measurements for target, land and ocean retrievals, respectively. In the overpass averaged results, the bias and SD 


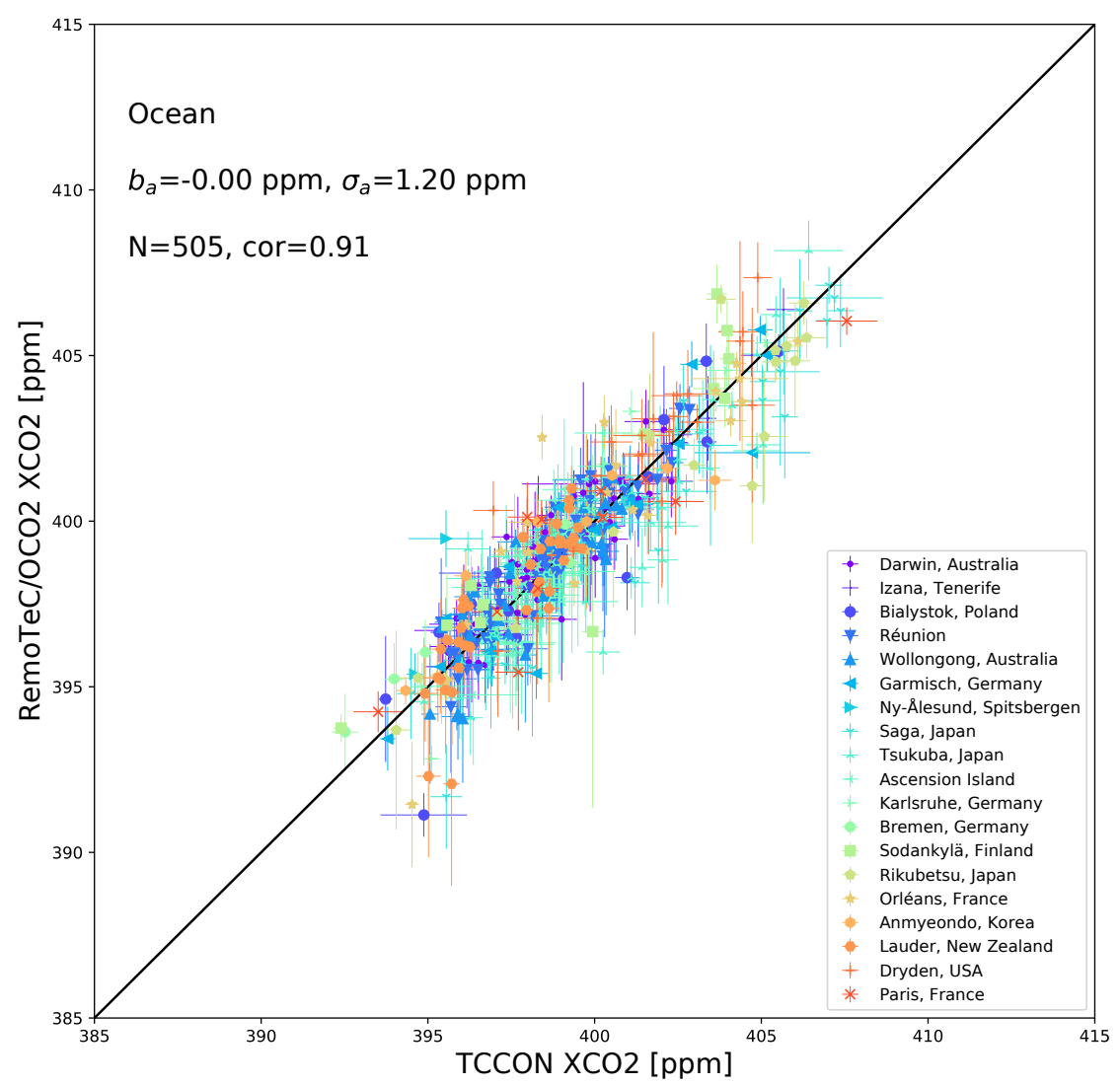

Figure 7. Same as Fig. 5, but for OCO-2 ocean type measurements obtained under glint mode.

$\left(b_{\mathrm{a}}, \sigma_{\mathrm{a}}\right)$ are $(-0.07,1.24),(0.00,1.36)$ and $(0.00,1.20) \mathrm{ppm}$ for target, land and ocean retrievals, respectively. Before bias correction, the mean biases are $0.51,0.44$ and $0.75 \mathrm{ppm}$ for the above three type of retrievals, respectively. The bias correction mainly improves the mean bias though the SDs are also reduced by $\sim 0.1 \mathrm{ppm}$ for land retrievals.

Figures 8, 9 and 10 show the bias $\left(b_{\mathrm{a}}\right)$ at each TCCON site as a function of its latitude for the target, land and ocean types of retrievals. The mean $\left(\overline{b_{\mathrm{a}}}\right)$ and the $\mathrm{SD}\left(\sigma_{\mathrm{s}}\right)$ of all the biases are also derived. Stations with less than five valid points have been excluded from the analysis. The number of stations used in the validation are 10, 17 and 18 for target, land and ocean retrievals, respectively. Within those stations, most of them have a bias less than $0.5 \mathrm{ppm}$ for both land and ocean retrievals.

In Fig. 8, the remaining $X_{\mathrm{CO}_{2}}$ bias for target observations varies from $-0.81 \mathrm{ppm}$ (Tsukuba, Japan) to $0.47 \mathrm{ppm}$ (Lauder, New Zealand). The developed bias correction reduces the station-to-station variability from 0.54 to $0.35 \mathrm{ppm}$. The effect of the bias correction is largest for Lamont, Dryden and Darwin stations $(>0.50 \mathrm{ppm}$ on the mean station bias) while in other stations the difference is small. This happens because the goodness of fit is highly correlated with surface albedo and thus make the corrections apparently to regions with large albedos. Land retrievals as shown in Fig. 9, validated among 17 stations, have a station-to-station variability of $0.41 \mathrm{ppm}$. The remaining bias varies from $-0.66 \mathrm{ppm}$ (Lamont, OK, USA) to $1.03 \mathrm{ppm}$ (Sodankylä, Finland). Here, most stations have similar biases as found for the corresponding target observations. The bias correction also helps to reduce the station-to-station variability for land retrievals although not that much. Among all the stations, Tsukuba station in Japan has relatively larger SD of $2.07 \mathrm{ppm}$. For retrievals in Figs. 8 and 9, there is a tendency for validations over stations in higher-latitude areas have relatively larger biases in both the northern and southern hemispheres. In addition, target observations have a smaller station-to-station variability than land observations although different TCCON stations are involved.

For ocean retrievals, since we only subtract swathdependent bias and a mean bias, the station-to-station variability $(0.44 \mathrm{ppm})$ is the same before and after bias correction. The biases vary from $-0.86 \mathrm{ppm}$ (Saga, Japan) to $0.75 \mathrm{ppm}$ (Bremen, Germany). There is no clear indication of latitude-dependent bias variation.

Moreover, we investigated temporal variations in RemoTeC/OCO-2 $X_{\mathrm{CO}_{2}}$ retrievals. As shown in Fig. 1, seasonal $X_{\mathrm{CO}_{2}}$ variation features in the Northern Hemisphere 


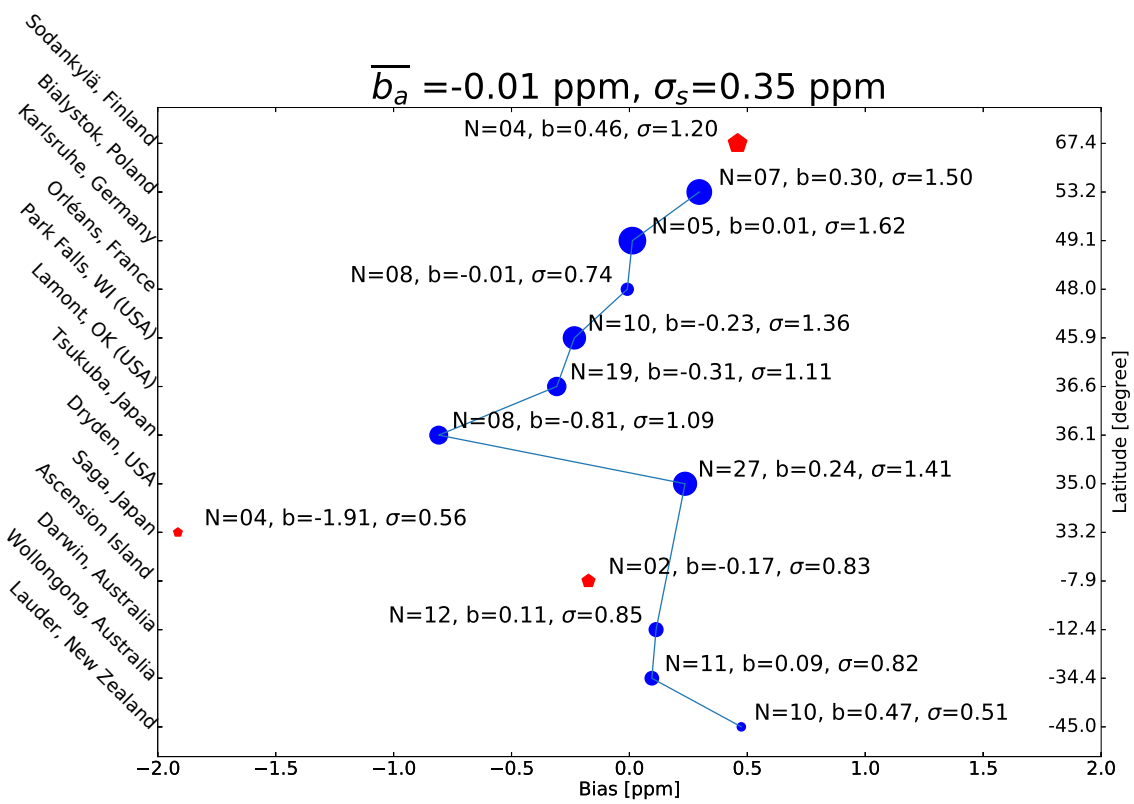

Figure 8. The dependence of the bias between RemoTeC/OCO-2 target $X_{\mathrm{CO}_{2}}$ retrievals coincident with TCCON data on the latitude of each station. Shown are the averaged results for bias-corrected $X_{\mathrm{CO}_{2}}$ retrievals. Stations with less than five collocation points (marked with red pentagon) should be interpreted with care and are therefore excluded from the calculation of the derived parameters including mean bias $\left(\overline{b_{\mathrm{a}}}\right)$ and the station-to-station variability $\left(\sigma_{\mathrm{S}}\right)$. For each station, number of valid points $(N)$, bias $(b)$ and $\mathrm{SD}(\sigma)$ are listed next to the dot point. The size of each dot represents the SD of the difference at each station.

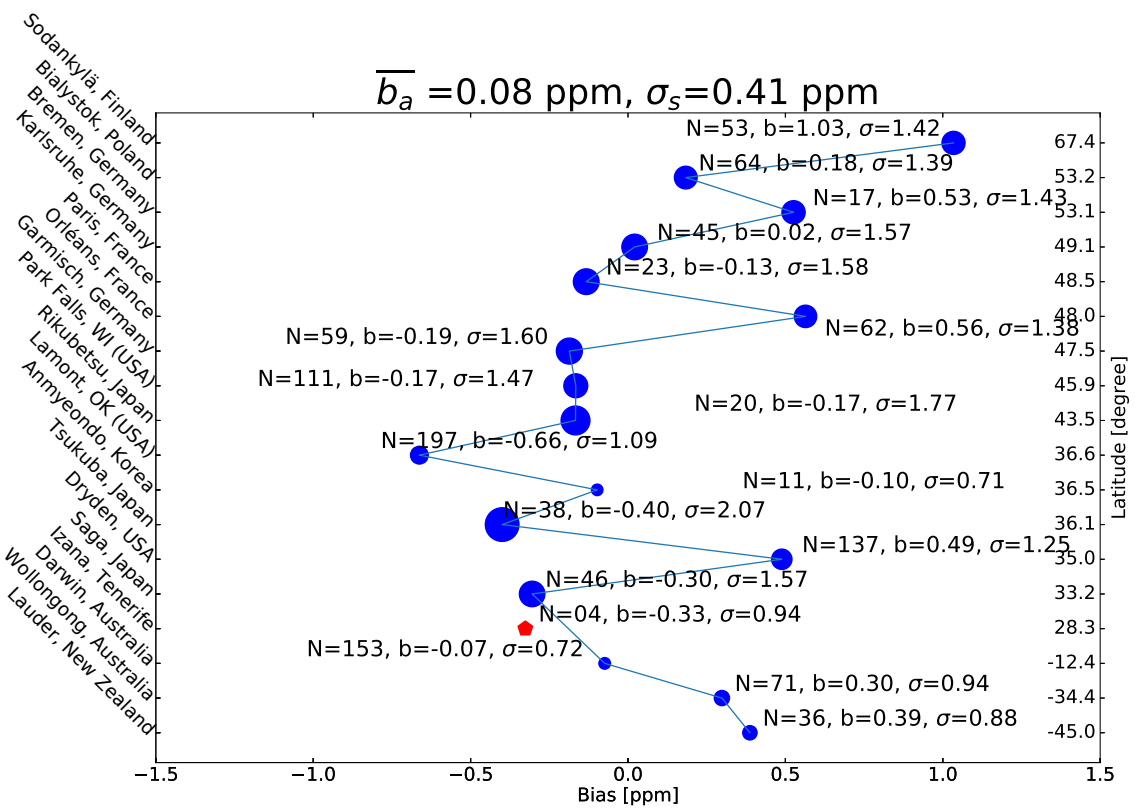

Figure 9. Same as Fig. 8, but for OCO-2 land type measurements obtained under nadir and glint modes.

can be captured well by both RemoTeC/OCO-2 retrievals and TCCON measurements. At the Southern Hemisphere, the $X_{\mathrm{CO}_{2}}$ is more stable throughout the whole time range. Figure 11 shows the time series of $X_{\mathrm{CO}_{2}}$ difference between TCCON measurements and $X_{\mathrm{CO}_{2}}$ retrievals from OCO-2 tar- get, land and ocean types of measurements. At most stations, no time-dependent biases can be clearly observed. For some stations in the Northern Hemisphere like Sodankylä, Bremen and Paris, time-dependent features can also be attributed to inhomogeneous seasonal data distribution. There are some 


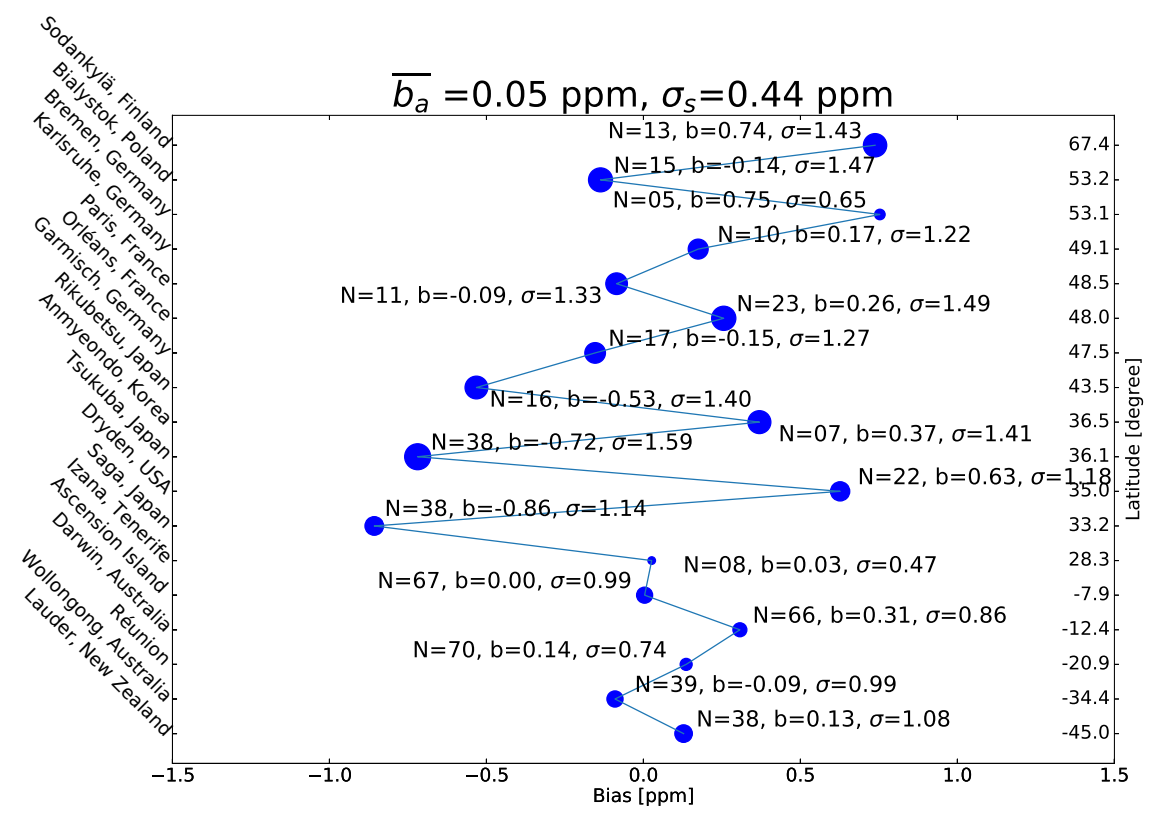

Figure 10. Same as Fig. 8, but for OCO-2 ocean type measurements obtained under glint mode.

outliers in $X_{\mathrm{CO}_{2}}$ retrievals from both land and ocean glint observations, such as those at the Tsukuba over land and Lauder over ocean, that need further investigation.

Finally, we check the SRA, which is derived for all three types of observations. For each station, all the data regardless of the year are sorted into four intervals of a calendar year. Table 3 summarizes seasonal bias per station, SD of biases per season, seasonal variability ("Seas") and the SRA value. The derived SRA of $0.52 \mathrm{ppm}$ is close to the requirement of $0.50 \mathrm{ppm}$ as discussed by Dils et al. (2014). Here, the developed bias correction helps to improve the SRA from 0.60 to $0.52 \mathrm{ppm}$. In stations where seasonal variability can be calculated, the value is generally around $0.30 \mathrm{ppm}$ except stations Rikubetsu (0.71 ppm) and Saga (0.43 ppm) in Japan. In Table 3 the SRA values are mainly driven by large negative biases from Rikubetsu, Tsukuba and Saga stations in Japan. Further investigations are needed to diagnose the remaining larger biases in certain season over stations in Japan.

\subsection{Importance of intensity offset}

As mentioned in Sect. 3, the implementation of the RemoTeC algorithm, used in this study, fits an intensity offset for all three OCO-2 bands. In previous GOSAT retrievals we only fit intensity offset for the NIR band. To identify its importance, we performed the same retrieval as in Fig. 6 but without fitting intensity offset in the SWIR-1 and SWIR-2 bands. Figure 12 shows that without fitting intensity offsets in the SWIR-1 and SWIR-2 bands the validation exhibits a negative bias of $-2.95 \mathrm{ppm}$ and the SD increased by $\sim 0.5 \mathrm{ppm}$.

As shown in Fig. 13, in the SWIR-1 and SWIR-2 bands the fitted intensity offsets are proportional to the mean radi- ance with a slope of 0.0025 and 0.0035 , respectively. This slope is about two times larger than that of noise. Generally, the fitted intensity offset in these two bands are $\sim 0.4 \%$ of the corresponding mean radiance. There are no clear timedependent features in the fitted intensity offset. The intensity offset in the $\mathrm{O}_{2}$ A band shows a less strong dependence on the signal level itself. Here, it could be partly introduced by light reflection by degraded anti-reflection coating on the focal plane array (Crisp et al., 2017). However, this can not explain the amount of intensity offset retrieved in our algorithm for the SWIR-1 and SWIR-2 bands since for those channels much thicker and higher index anti-reflection coatings are used (Crisp et al., 2017). Potential causes could be stray light from reflection of nearby ground pixels or from components of the optical system.

\section{Discussion}

As we mentioned before, OCO-2 level-2 products delivered by the ACOS retrieval algorithm are also validated with collocated TCCON data by Wunch et al. (2017). Before comparing our results with the results in Wunch et al. (2017), we need to point out several differences between the validation approach by Wunch et al. (2017) and our study. (1) The considered time range of the study by Wunch et al. (2017) is from September 2014 to January 2017. (2) A collocation criterion of $5^{\circ}$ in latitude and $10^{\circ}$ in longitude is applied for most stations but, for Caltech and Dryden and those located on the Southern Hemisphere, a specific local collocation criterion is employed. (3) Daily median values of both OCO-2 retrievals and TCCON are used for comparison. (4) Obser- 

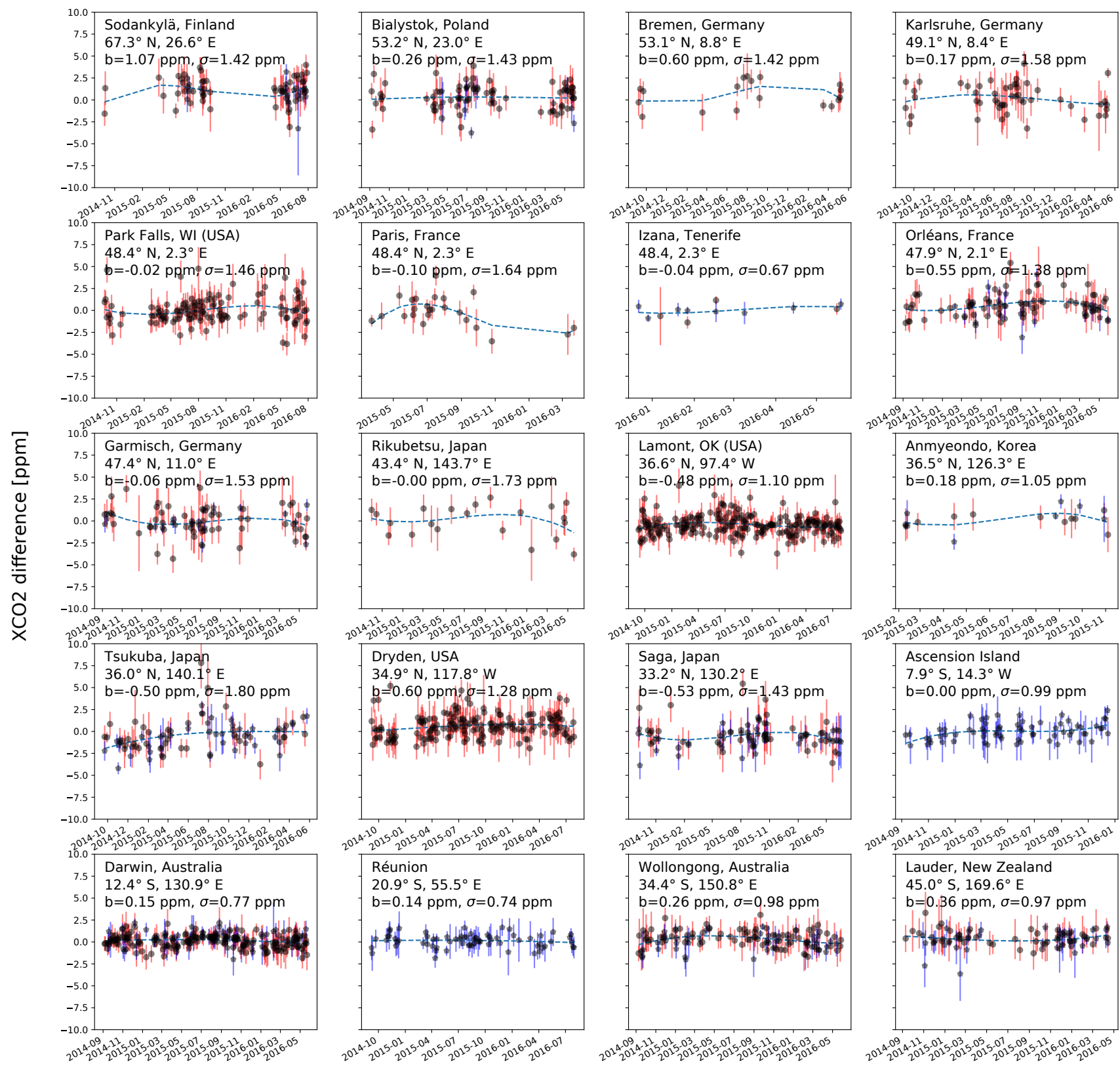

Time series

Figure 11. Time variation of $X_{\mathrm{CO}_{2}}$ difference between retrievals from OCO-2 observations over land (red dots) and ocean (blue pentagon) and collocated TCCON measurements for each TCCON station. SD of individual TCCON measurement and satellite retrievals are presented with the length of bar. In each subplot, the overall bias $(b)$, SD $(\sigma)$ and site location in latitude and longitude are included. The shown results here are bias-corrected data used in Table 3. An second-order polynomial (blue dot lines) is fitted for distinguishing the time-variation of biases.

vations over land under nadir and glint modes are validated separately. (5) The employed filter settings and bias corrections are also different from here.

For bias-corrected data, albeit with so many differences, we still see a lot of common aspects when looking at the SD and station-to-station variability in Wunch et al. (2017). For example, for the results under warn level 11 (the best
$50 \%$ of the total L2 data; see Mandrake et al., 2015, for more details on warn level) the SD of the difference (OCO2-TCCON) for land retrievals is around $1.3 \mathrm{ppm}$. Looking at station-to-station variability for ACOS land retrievals, the $\sigma_{\mathrm{s}}$ is $\sim 0.45 \mathrm{ppm}$ over 12 stations. For ocean glint retrievals, the $\sigma_{\mathrm{s}}$ is $0.46 \mathrm{ppm}$ over 9 stations. These values are more or less 
Table 3. Bias between $X_{\mathrm{CO}_{2}}$ retrieval from RemoTeC/OCO-2, including target, land and ocean retrievals, and TCCON data at individual stations in four different time intervals of a calendar year (Q1: 1 January-31 March; Q2: 1 April-30 June; Q3: 1 July-30 September; Q4: 1 October-31 December). For each time interval, we only use data from stations with more than five collocated points. In each table cell, bias, SD and number of points are included and those with larger standard error $(\sigma / \sqrt{N}>0.5 \mathrm{ppm})$ after bias correction will also be neglected as done by Dils et al. (2014). For stations with all four seasonal biases, the SD of these four biases ("Seas") are also calculated. This parameter is an indicator of their seasonal variability.

\begin{tabular}{|c|c|c|c|c|c|c|}
\hline Stations & Q1 & Q2 & Q3 & Q4 & Seas & Reference \\
\hline Sodankylä, Finland $\left(67.3^{\circ} \mathrm{N}, 26.6^{\circ} \mathrm{E}\right)$ & - & $0.70(1.49,39)$ & $1.18(1.28,30)$ & - & - & Kivi et al. (2014) \\
\hline Białystok, Poland $\left(53.2^{\circ} \mathrm{N}, 23.0^{\circ} \mathrm{E}\right)$ & $-0.34(1.34,14)$ & $0.02(1.31,40)$ & $0.62(1.60,25)$ & $0.02(0.93,7)$ & 0.34 & Deutscher et al. (2015) \\
\hline Bremen, Germany $\left(53.1^{\circ} \mathrm{N}, 8.8^{\circ} \mathrm{E}\right)$ & - & $-0.04(0.95,7)$ & $1.04(1.20,14)$ & - & - & Notholt et al. (2014) \\
\hline Karlsruhe, Germany $\left(49.1^{\circ} \mathrm{N}, 8.4^{\circ} \mathrm{E}\right)$ & _ & $-0.16(1.37,25)$ & $0.09(1.75,24)$ & $0.59(0.75,6)$ & _- & Hase et al. (2015) \\
\hline Park Falls, WI (USA) $\left(48.4^{\circ} \mathrm{N}, 2.3^{\circ} \mathrm{E}\right)$ & $-0.14(1.16,17)$ & $-0.37(1.53,38)$ & $0.10(1.52,46)$ & $-0.44(1.27,20)$ & 0.21 & Wennberg et al. (2014) \\
\hline Paris, France $\left(48.4^{\circ} \mathrm{N}, 2.3^{\circ} \mathrm{E}\right)$ & - & $-0.15(1.10,11)$ & $0.33(1.44,19)$ & - & - & Te et al. (2014) \\
\hline Izana, Tenerife $\left(48.4^{\circ} \mathrm{N}, 2.3^{\circ} \mathrm{E}\right)$ & $-0.24(0.73,7)$ & - & - & _- & _- & Blumenstock et al. (2014) \\
\hline Orléans, France $\left(47.9^{\circ} \mathrm{N}, 2.1^{\circ} \mathrm{E}\right)$ & $0.36(1.01,19)$ & $0.34(1.04,34)$ & $0.32(1.81,25)$ & $0.98(1.47,15)$ & 0.28 & Warneke et al. (2014) \\
\hline Garmisch, Germany $\left(47.4^{\circ} \mathrm{N}, 11.0^{\circ} \mathrm{E}\right)$ & $-0.04(1.47,15)$ & $-0.49(1.56,28)$ & $0.02(1.34,23)$ & - & - & Sussmann and Rettinger (2014) \\
\hline Rikubetsu, Japan $\left(43.4^{\circ} \mathrm{N}, 143.7^{\circ} \mathrm{E}\right)$ & $-1.21(1.64,11)$ & $-0.13(1.64,13)$ & $0.81(1.03,6)$ & $-0.24(1.04,7)$ & 0.71 & Morino et al. (2016b) \\
\hline Lamont, OK (USA) $\left(36.6^{\circ} \mathrm{N}, 97.4^{\circ} \mathrm{W}\right)$ & $-0.71(1.06,55)$ & $-0.35(1.01,53)$ & $-0.51(1.29,59)$ & $-1.00(0.83,49)$ & 0.24 & Wennberg et al. (2016) \\
\hline Anmyeondo, South Korea $\left(36.5^{\circ} \mathrm{N}, 126.3^{\circ} \mathrm{E}\right)$ & $-0.26(0.58,5)$ & - & $0.67(0.85,7)$ & - & - & Goo et al. (2014) \\
\hline Tsukuba, Japan $\left(36.0^{\circ} \mathrm{N}, 140.1^{\circ} \mathrm{E}\right)$ & $-1.31(1.18,26)$ & $0.07(1.17,12)$ & - & $-1.00(1.17,29)$ & _- & Morino et al. (2016a) \\
\hline Dryden, USA $\left(34.9^{\circ} \mathrm{N}, 117.8^{\circ} \mathrm{W}\right)$ & $0.10(1.08,40)$ & $0.85(0.99,59)$ & $0.55(1.56,48)$ & $0.16(1.24,39)$ & 0.30 & Iraci et al. (2016) \\
\hline Saga, Japan $\left(33.2^{\circ} \mathrm{N}, 130.2^{\circ} \mathrm{E}\right)$ & $-1.24(0.80,14)$ & $-0.93(1.05,27)$ & $-0.32(1.86,24)$ & $-0.19(1.33,23)$ & 0.43 & Kawakami et al. (2014) \\
\hline Ascension Island $\left(7.9165^{\circ} \mathrm{S}, 14.3325^{\circ} \mathrm{W}\right)$ & $0.19(1.03,12)$ & $0.07(0.92,18)$ & $-0.04(0.99,14)$ & $-0.12(0.99,23)$ & 0.12 & Feist et al. (2014) \\
\hline Darwin, Australia $\left(12.4^{\circ} \mathrm{S}, 130.9^{\circ} \mathrm{E}\right)$ & $-0.21(0.88,55)$ & $0.01(0.71,61)$ & $0.38(0.58,49)$ & $0.04(0.81,66)$ & 0.21 & Griffith et al. (2014a) \\
\hline Réunion $\left(20.901^{\circ} \mathrm{S}, 55.485^{\circ} \mathrm{E}\right)$ & $0.10(0.69,9)$ & $-0.23(0.75,17)$ & $0.12(0.61,25)$ & $0.50(0.73,19)$ & 0.26 & De Mazière et al. (2014) \\
\hline Wollongong, Australia $\left(34.4^{\circ} \mathrm{S}, 150.8^{\circ} \mathrm{E}\right)$ & $0.04(0.98,41)$ & $0.26(0.93,17)$ & $0.21(1.18,26)$ & $0.19(0.76,37)$ & 0.08 & Griffith et al. (2014b) \\
\hline Lauder, New Zealand $\left(45.0^{\circ} \mathrm{S}, 169.6^{\circ} \mathrm{E}\right)$ & $0.19(0.99,29)$ & $0.53(0.67,10)$ & $0.13(0.92,8)$ & $0.31(0.97,37)$ & 0.15 & Sherlock et al. (2014) \\
\hline ALL & 0.52 & 0.42 & 0.43 & 0.54 & - & \\
\hline SRA & & SR $A$ & 0.52 & & & \\
\hline
\end{tabular}

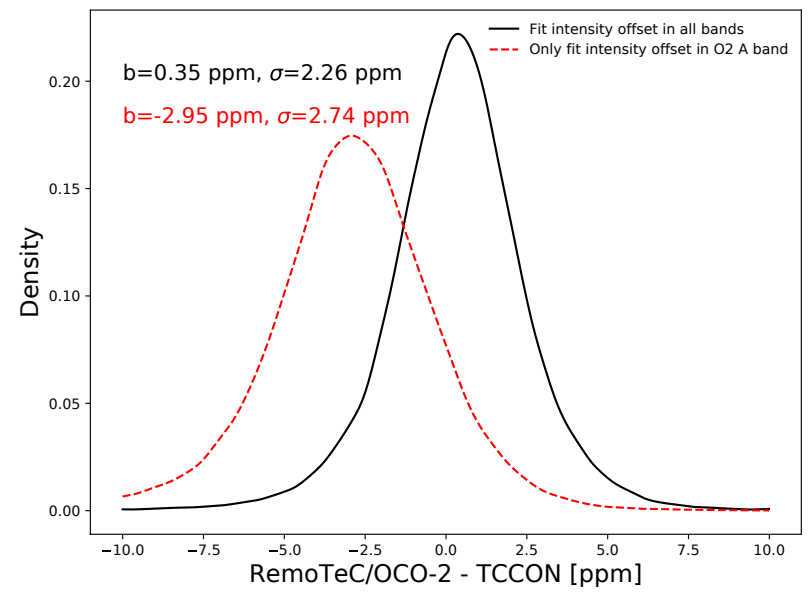

Figure 12. Density distributions of the $X_{\mathrm{CO}_{2}}$ differences between OCO-2 land retrievals and collocated TCCON data for two different retrieval settings. In the black solid line we fit intensity offsets in all three OCO-2 bands while in the red dashed line we only fit the intensity offset in $\mathrm{O}_{2} \mathrm{~A}$ band. Here we only do algorithm convergence filtering for both and take the intersection of them for fair comparison. The bias $b$ and sounding precision $\sigma$ for each retrieval are included. the same, albeit a bit higher, as what we see in the validation in Figs. 9 and 10.

In order to perform a more direct comparison between ACOS and RemoTeC, we took the common data points that passed quality filtering for both algorithms for the period under consideration of this study. In total, we collect 34560 individual retrievals collocated with 18 TCCON stations. These retrievals only take $31.0 \%$ of total land retrievals in Fig. 2, which means we have quite different data coverage with ACOS/OCO-2. As expected, after bias correction, the results between ACOS and RemoTeC are similar with a bias, $\mathrm{SD}$ and station-to-station bias of $-0.02,1.36$ and $0.44 \mathrm{ppm}$ in RemoTeC and 0.13, 1.31 and 0.55 ppm in ACOS. However, when looking at the results before bias correction the differences are larger. Before bias correction, the overall bias and SD are 0.58 and $1.62 \mathrm{ppm}$ in RemoTeC/OCO2 retrievals and -1.38 and $1.89 \mathrm{ppm}$ in $\mathrm{ACOS} / \mathrm{OCO}-2$ retrievals. When looking at overpass averaging results, in total 646 cases, RemoTeC/OCO-2 retrievals have a mean bias of $0.67 \mathrm{ppm}$ with an SD of $1.43 \mathrm{ppm}$, while ACOS/OCO-2 retrievals have a mean bias of $-1.04 \mathrm{ppm}$ with an SD of $1.53 \mathrm{ppm}$. The station-to-station biases are 0.47 and $0.63 \mathrm{ppm}$ for RemoTeC/OCO-2 and ACOS/OCO-2, respectively. The ACOS product depends much more on bias correction than RemoTeC. Possible reasons are the zero-level offset fits in RemoTeC that are not performed by ACOS or the difference in the treatment of aerosols. 

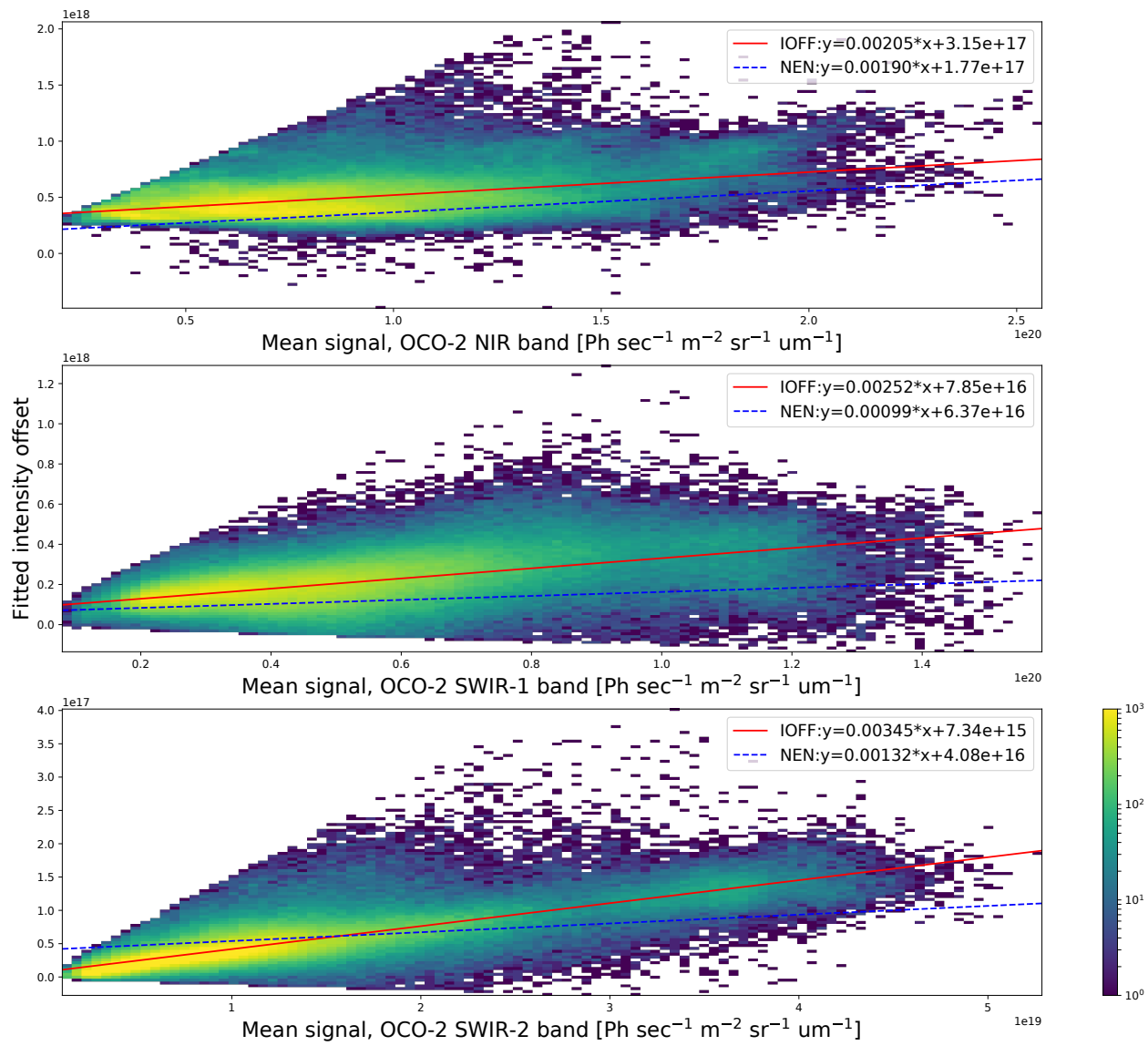

Figure 13. Variation of fitted intensity offset with respect to mean signals measured in each OCO-2 band for observations over land. Linear regression fit for the intensity offset (IOFF) and noise equivalent radiance (NEN) is overplotted along with fitted coefficients on top right. Different colors represent the frequency of point occurrence.

$X_{\mathrm{CO}_{2}}$ retrievals from GOSAT measurements using the RemoTeC algorithm have also been validated with TCCON data (Butz et al., 2011; Guerlet et al., 2013b; Dils et al., 2014; Buchwitz et al., 2017b). There are several improvements on the RemoTeC/GOSAT $X_{\mathrm{CO}_{2}}$ retrieval quality since the first report by Butz et al. (2011). Here we will use the latest results over land reported by Buchwitz et al. (2017a). It should be noted that there are quite a few differences between RemoTeC/GOSAT and RemoTeC/OCO-2 including instrument polarization sensitivity, collocation criteria, filtering options and so on. In the validation between RemoTeC/GOSAT $X_{\mathrm{CO}_{2}}$ retrievals and TCCON data, the sounding precision is $1.9 \mathrm{ppm}$ with a station-to-station variability (estimated over 12 stations) of $0.43 \mathrm{ppm}$. The derived SRA is $0.51 \mathrm{ppm}$. Looking at those overall statistic values, there are no significant differences between $X_{\mathrm{CO}_{2}}$ retrievals from RemoTeC/OCO-2 and RemoTeC/GOSAT. Before bias correction, the major difference between RemoTeC/OCO2 and RemoTeC/GOSAT is the overall bias $(0.35 \mathrm{ppm}$ vs. -2.25 ). However, further investigation is needed to identify the difference between $X_{\mathrm{CO}_{2}}$ retrievals from those two satellites, especially over regions where TCCON data are not available.

\section{Conclusions}

In this paper, we extended and adapted the full physics retrieval algorithm RemoTeC, previously applied to GOSAT, for OCO-2 satellite measurements. The algorithm was applied to OCO-2 nadir, glint and target observations obtained over land and ocean (glint only). We defined both an a posteriori data filtering approach and bias correction as a function of the swath position by comparing with TCCON. Additionally, we introduced a linear bias correction for land observations as a function of the spectral fit quality. Comparison of the retrieved $X_{\mathrm{CO}_{2}}$ with collocated ground-based TCCON stations showed that for both land and ocean observations our retrieval results exhibit a residual bias less than $0.10 \mathrm{ppm}$ with an SD around $1.30 \mathrm{ppm}$ (for overpass means) and a station-to-station variability variation around $0.40 \mathrm{ppm}$. Among the individual TCCON stations, the biases are generally less than $0.50 \mathrm{ppm}$. In land retrievals, middle- to 
high-latitude areas have relatively larger biases and in ocean retrievals no latitude-dependent bias can be clearly seen. The target observations have a station-to-station variability around $0.35 \mathrm{ppm}$ which approaches the systematic error required for regional $\mathrm{CO}_{2}$ source-sink determination (Chevallier et al., 2005; Houweling et al., 2010; Chevallier et al., $2014 b$, a). The better comparison with TCCON for target mode retrievals compared to regular land retrievals could be attributed to the fact that under the target mode the OCO-2 satellite is directly looking at the place where TCCON sites are located and this provides a better collocation and therefore prevents apparent biases caused by local $X_{\mathrm{CO}_{2}}$ variations. Time series validation indicates that RemoTeC/OCO2 retrieval results can capture well the seasonal cycle of $X_{\mathrm{CO}_{2}}$ in both hemispheres and no time-dependent bias can be clearly observed in the retrieval. The SRA investigated over 66 time intervals of collocated stations has a value of $0.52 \mathrm{ppm}$. Most of stations have a seasonal variability around $0.30 \mathrm{ppm}$ except for those in Japan. For the $X_{\mathrm{CO}_{2}}$ retrieval from OCO-2 measurements, we see that intensity offsets need to be fitted for all three bands otherwise a larger bias $(2.50 \mathrm{ppm})$ and SD $(0.50 \mathrm{ppm})$ would be introduced in the results.

Data availability. The OCO-2 data (version 7) used here were produced by the OCO-2 project at the Jet Propulsion Laboratory, California Institute of Technology, and obtained from the OCO-2 data archive maintained at the NASA Goddard Earth Science Data and Information Services Center (https://daac.gsfc.nasa.gov/). TCCON data were obtained from the TCCON Data Archive, hosted by the Carbon Dioxide Information Analysis Center (CDIAC) at that time. Since October 2017, the TCCON Data Archive is hosted by CaltechDATA, California Institute of Technology, CA (US), https://doi. org/10.14291/tccon.archive/1348407. The RemoTeC/OCO-2 $X_{\mathrm{CO}_{2}}$ retrievals used in this paper are available upon request from Lianghai Wu (1.wu@sron.nl).

\section{The Supplement related to this article is available online at https://doi.org/10.5194/amt-11-3111-2018-supplement.}

Competing interests. The authors declare that they have no conflict of interest.

Acknowledgements. This research was funded by the Netherlands Space Office as part of the User Support Programme Space Research under project ALW-GO/15-23. We are grateful to Université Pierre et Marie Curie, the French space agency CNES and Région ĺle-de-France for their financial contributions as well as to Institut Pierre-Simon Laplace for support and facilities.

Edited by: Joanna Joiner

Reviewed by: Christopher O'Dell and two anonymous referees

\section{References}

Aben, I., Hasekamp, O., and Hartmann, W.: Uncertainties in the space-based measurements of $\mathrm{CO}_{2}$ columns due to scattering in the Earth's atmosphere, J. Quant. Spectrosc. Ra., 104, 450-459, https://doi.org/10.1016/j.jqsrt.2006.09.013, 2007.

Baker, D. F., Bösch, H., Doney, S. C., O'Brien, D., and Schimel, D. S.: Carbon source/sink information provided by column $\mathrm{CO}_{2}$ measurements from the Orbiting Carbon Observatory, Atmos. Chem. Phys., 10, 4145-4165, https://doi.org/10.5194/acp-104145-2010, 2010.

Basu, S., Krol, M., Butz, A., Clerbaux, C., Sawa, Y., Machida, T., Matsueda, H., Frankenberg, C., Hasekamp, O. P., and Aben, I.: The seasonal variation of the $\mathrm{CO}_{2}$ flux over Tropical Asia estimated from GOSAT, CONTRAIL, and IASI, Geophys. Res. Lett., 41, 1809-1815, https://doi.org/10.1002/2013GL059105, 2014.

Blumenstock, T., Hase, F., Schneider, M., Garcia, O. E., and Sepulveda, E.: TCCON data from Izana (ES), Release GGG2014.R0, TCCON Data Archive, hosted by CaltechDATA, https://doi.org/10.14291/tccon.ggg2014.izana01.R0/1149295, 2014.

Boesch, H., Baker, D., Connor, B., Crisp, D., and Miller, C.: Global characterization of $\mathrm{CO}_{2}$ column retrievals from shortwave-infrared satellite observations of the Orbiting Carbon Observatory-2 mission, Remote Sens., 3, 270-304, 2011.

Bösch, H., Toon, G. C., Sen, B., Washenfelder, R. A., Wennberg, P. O., Buchwitz, M., de Beek, R., Burrows, J. P., Crisp, D., Christi, M., Connor, B. J., Natraj, V., and Yung, Y. L.: Space=based near-infrared $\mathrm{CO}_{2}$ measurements: Testing the Orbiting Carbon Observatory retrieval algorithm and validation concept using SCIAMACHY observations over Park Falls, Wisconsin, J. Geophys. Res.-Atmos., 111, D23302, https://doi.org/10.1029/2006JD007080, 2006.

Buchwitz, M., Rozanov, V. V., and Burrows, J. P.: A nearinfrared optimized DOAS method for the fast global retrieval of atmospheric $\mathrm{CH}_{4}, \mathrm{CO}, \mathrm{CO}_{2}, \mathrm{H}_{2} \mathrm{O}$, and $\mathrm{N}_{2} \mathrm{O}$ total column amounts from SCIAMACHY Envisat-1 nadir radiances, J. Geophys. Res.-Atmos., 105, 15231-15245, https://doi.org/10.1029/2000JD900191, 2000.

Buchwitz, M., de Beek, R., Burrows, J. P., Bovensmann, H., Warneke, T., Notholt, J., Meirink, J. F., Goede, A. P. H., Bergamaschi, P., Körner, S., Heimann, M., and Schulz, A.: Atmospheric methane and carbon dioxide from SCIAMACHY satellite data: initial comparison with chemistry and transport models, Atmos. Chem. Phys., 5, 941-962, https://doi.org/10.5194/acp-5941-2005, 2005.

Buchwitz, M., Dils, B., Boesch, H., Brunner, D., Butz, A., Crevoisier, C., Detmers, R., Frankenberg, C., Hasekamp, O., Hewson, W., Laeng, A., Noël, S., Notholt, J., Parker, R., Reuter, M., Schneising, O., Somkuti, P., Sundström, A., and De Wachter, E.: ESA Climate Change Initiative (CCI) Product Validation and Intercomparison Report (PVIR) for the Essential Climate Variable (ECV) Greenhouse Gases (GHG) for data set Climate Research Data Package No. 4 (CRDP\# 4), Technical Note, 4, 253, http://www.esa-ghg-cci.org/?q=node/95 (last access: 28 May 2018), 2017a.

Buchwitz, M., Reuter, M., Schneising, O., Hewson, W., Detmers, R., Boesch, H., Hasekamp, O., Aben, I., Bovensmann, H., Burrows, J., Butz, A., Chevallier, F., Dils, B., Frankenberg, C., Hey- 
mann, J., Lichtenberg, G., Maziè re, M. D., Notholt, J., Parker, R., Warneke, T., Zehner, C., Griffith, D., Deutscher, N., Kuze, A., Suto, H., and Wunch, D.: Global satellite observations of column averaged carbon dioxide and methane: The GHG-CCI XCO2 and XCH4 CRDP3 data set, Remote Sens. Environ., 203, 276-295, https://doi.org/10.1016/j.rse.2016.12.027, 2017b.

Butz, A., Hasekamp, O. P., Frankenberg, C., and Aben, I.: Retrievals of atmospheric $\mathrm{CO}_{2}$ from simulated space-borne measurements of backscattered near-infrared sunlight: accounting for aerosol effects, Appl. Opt., 48, 3322-3336, 2009.

Butz, A., Hasekamp, O., Frankenberg, C., Vidot, J., and Aben, I.: $\mathrm{CH}_{4}$ retrievals from space-based solar backscatter measurements: Performance evaluation against simulated aerosol and cirrus loaded scenes, J. Geophys. Res.-Atmos., 115, D24302, https://doi.org/10.1029/2010JD014514, 2010.

Butz, A., Guerlet, S., Hasekamp, O., Schepers, D., Galli, A., Aben, I., Frankenberg, C., Hartmann, J.-M., Tran, H., Kuze, A., Keppel-Aleks, G., Toon, G., Wunch, D., Wennberg, P., Deutscher, N., Griffith, D., Macatangay, R., Messerschmidt, J., Notholt, J., and Warneke, T.: Toward accurate $\mathrm{CO}_{2}$ and $\mathrm{CH}_{4}$ observations from GOSAT, Geophys. Res. Lett., 38, L14812, https://doi.org/10.1029/2011GL047888, 2011.

Butz, A., Galli, A., Hasekamp, O., Landgraf, J., Tol, P., and Aben, I.: TROPOMI aboard Sentinel-5 Precursor: Prospective performance of $\mathrm{CH}_{4}$ retrievals for aerosol and cirrus loaded atmospheres, Remote Sens. Environ., 120, 267-276, 2012.

Caldeira, K. and Wickett, M. E.: Oceanography: anthropogenic carbon and ocean pH, Nature, 425, 365-365, 2003.

Chédin, A., Hollingsworth, A., Scott, N. A., Serrar, S., Crevoisier, C., and Armante, R.: Annual and seasonal variations of atmospheric $\mathrm{CO}_{2}, \mathrm{~N}_{2} \mathrm{O}$ and $\mathrm{CO}$ concentrations retrieved from NOAA/TOVS satellite observations, Geophys. Res. Lett., 29, 110-1-110-4, https://doi.org/10.1029/2001GL014082, 2002.

Chevallier, F., Engelen, R. J., and Peylin, P.: The contribution of AIRS data to the estimation of $\mathrm{CO}_{2}$ sources and sinks, Geophys. Res. Lett., 32, L23801, https://doi.org/10.1029/2005GL024229, 2005.

Chevallier, F., Buchwitz, M., Houweling, S., Aben, I., Palmer, P. I., van Leeuwen, T., and Bergamaschi, P.: ESA Climate Change Initiative (CCI) User Requirements Document (URD) for the Essential Climate Variable (ECV) Greenhouse Gases (GHG), technical note, p. 38, available at: http://www.esa-ghg-cci.org/?q=webfm send/173 (last access: 28 May 2018), 2014a.

Chevallier, F., Palmer, P. I., Feng, L., Boesch, H., O’Dell, C. W., and Bousquet, P.: Toward robust and consistent regional $\mathrm{CO}_{2}$ flux estimates from in situ and spaceborne measurements of atmospheric $\mathrm{CO}_{2}$, Geophys. Res. Lett., 41, 1065-1070, $2014 \mathrm{~b}$.

Cox, C. and Munk, W.: Statistics of the sea surface derived from sun glitter, J. Mar. Res., 13, 198-227, 1954.

Cox, P. M., Betts, R. A., Jones, C. D., Spall, S. A., and Totterdell, I. J.: Acceleration of global warming due to carbon-cycle feedbacks in a coupled climate model, Nature, 408, 184-187, 2000.

Crevoisier, C., Chédin, A., Matsueda, H., Machida, T., Armante, R., and Scott, N. A.: First year of upper tropospheric integrated content of $\mathrm{CO}_{2}$ from IASI hyperspectral infrared observations, Atmos. Chem. Phys., 9, 4797-4810, https://doi.org/10.5194/acp9-4797-2009, 2009.

Crisp, D., Atlas, R., Breon, F.-M., Brown, L., Burrows, J., Ciais, P., Connor, B., Doney, S., Fung, I., Jacob, D., Miller, C., O’Brien,
D., Pawson, S., Randerson, J., Rayner, P., Salawitch, R., Sander, S., Sen, B., Stephens, G., Tans, P., Toon, G., Wennberg, P., Wofsy, S., Yung, Y., Kuang, Z., Chudasama, B., Sprague, G., Weiss, B., Pollock, R., Kenyon, D., and Schroll, S.: The Orbiting Carbon Observatory (OCO) mission, Adv. Space Res., 34, 700-709, https://doi.org/10.1016/j.asr.2003.08.062, 2004.

Crisp, D., Fisher, B. M., O’Dell, C., Frankenberg, C., Basilio, R., Bösch, H., Brown, L. R., Castano, R., Connor, B., Deutscher, N. M., Eldering, A., Griffith, D., Gunson, M., Kuze, A., Mandrake, L., McDuffie, J., Messerschmidt, J., Miller, C. E., Morino, I., Natraj, V., Notholt, J., O’Brien, D. M., Oyafuso, F., Polonsky, I., Robinson, J., Salawitch, R., Sherlock, V., Smyth, M., Suto, H., Taylor, T. E., Thompson, D. R., Wennberg, P. O., Wunch, D., and Yung, Y. L.: The ACOS $\mathrm{CO}_{2}$ retrieval algorithm - Part II: Global $X_{\mathrm{CO}_{2}}$ data characterization, Atmos. Meas. Tech., 5, 687707, https://doi.org/10.5194/amt-5-687-2012, 2012.

Crisp, D., Pollock, H. R., Rosenberg, R., Chapsky, L., Lee, R. A. M., Oyafuso, F. A., Frankenberg, C., O’Dell, C. W., Bruegge, C. J., Doran, G. B., Eldering, A., Fisher, B. M., Fu, D., Gunson, M. R., Mandrake, L., Osterman, G. B., Schwandner, F. M., Sun, K., Taylor, T. E., Wennberg, P. O., and Wunch, D.: The on-orbit performance of the Orbiting Carbon Observatory-2 (OCO-2) instrument and its radiometrically calibrated products, Atmos. Meas. Tech., 10, 59-81, https://doi.org/10.5194/amt-10-59-2017, 2017.

De Mazière, M., Sha, M. K., Desmet, F., Hermans, C., Scolas, F., Kumps, N., Metzger, J.-M., Duflot, V., and Cammas, J.-P.: TCCON data from Réunion Island (RE), Release GGG2014.R0, TCCON Data Archive, hosted by CaltechDATA, https://doi.org/10.14291/tccon.ggg2014.reunion01.R0/1149288, 2014.

Detmers, R. G., Hasekamp, O., Aben, I., Houweling, S., van Leeuwen, T. T., Butz, A., Landgraf, J., Köhler, P., Guanter, L., and Poulter, B.: Anomalous carbon uptake in Australia as seen by GOSAT, Geophys. Res. Lett., 42, 8177-8184, https://doi.org/10.1002/2015GL065161, 2015GL065161, 2015.

Deutscher, N. M., Notholt, J., Messerschmidt, J., Weinzierl, C., Warneke, T., Petri, C., Grupe, P., and Katrynski, K.: TCCON data from Bialystok (PL), Release GGG2014.R1, TCCON Data Archive, hosted by CaltechDATA, https://doi.org/10.14291/tccon.ggg2014.bialystok01.R1/1183984, 2015.

Dils, B., Buchwitz, M., Reuter, M., Schneising, O., Boesch, H., Parker, R., Guerlet, S., Aben, I., Blumenstock, T., Burrows, J. P., Butz, A., Deutscher, N. M., Frankenberg, C., Hase, F., Hasekamp, O. P., Heymann, J., De Mazière, M., Notholt, J., Sussmann, R., Warneke, T., Griffith, D., Sherlock, V., and Wunch, D.: The Greenhouse Gas Climate Change Initiative (GHG-CCI): comparative validation of GHG-CCI SCIAMACHY/ENVISAT and TANSO-FTS/GOSAT $\mathrm{CO}_{2}$ and $\mathrm{CH}_{4}$ retrieval algorithm products with measurements from the TCCON, Atmos. Meas. Tech., 7, 1723-1744, https://doi.org/10.5194/amt-7-1723-2014, 2014.

Dubovik, O., Sinyuk, A., Lapyonok, T., Holben, B. N., Mishchenko, M., Yang, P., Eck, T. F., Volten, H., Munoz, O., Veihelmann, B. Zande Wim, J., Leon, J., Sorokin, M., and Slutsker, I.: Application of spheroid models to account for aerosol particle nonsphericity in remote sensing of desert dust, J. Geophys. Res.Atmos., 111, D11208, https://doi.org/10.1029/2005JD006619, 2006. 
Eldering, A., O’Dell, C. W., Wennberg, P. O., Crisp, D., Gunson, M. R., Viatte, C., Avis, C., Braverman, A., Castano, R., Chang, A., Chapsky, L., Cheng, C., Connor, B., Dang, L., Doran, G., Fisher, B., Frankenberg, C., Fu, D., Granat, R., Hobbs, J., Lee, R. A. M., Mandrake, L., McDuffie, J., Miller, C. E., Myers, V., Natraj, V., O'Brien, D., Osterman, G. B., Oyafuso, F., Payne, V. H., Pollock, H. R., Polonsky, I., Roehl, C. M., Rosenberg, R., Schwandner, F., Smyth, M., Tang, V., Taylor, T. E., To, C., Wunch, D., and Yoshimizu, J.: The Orbiting Carbon Observatory-2: first 18 months of science data products, Atmos. Meas. Tech., 10, 549-563, https://doi.org/10.5194/amt-10-549-2017, 2017.

Engelen, R. J., Andersson, E., Chevallier, F., Hollingsworth, A., Matricardi, M., McNally, A. P., Thépaut, J.-N., and Watts, P. D.: Estimating atmospheric $\mathrm{CO}_{2}$ from advanced infrared satellite radiances within an operational 4D-Var data assimilation system: Methodology and first results, J. Geophys. Res.-Atmos., 109, D18305, https://doi.org/10.1029/2004JD004777, 2004.

Farr, T. G., Rosen, P. A., Caro, E., Crippen, R., Duren, R., Hensley, S., Kobrick, M., Paller, M., Rodriguez, E., Roth, L., Seal, D., Shaffer, S., Shimada, J., Umland, J., Werner, M., Oskin, M., Burbank, D., and Alsdorf, D.: The shuttle radar topography mission, Rev. Geophys., 45, RG2004, https://doi.org/10.1029/2005RG000183, 2007.

Feist, D. G., Arnold, S. G., John, N., and Geibel, M. C.: TCCON data from Ascension Island (SH), Release GGG2014.R0, TCCON Data Archive, hosted by CaltechDATA, https://doi.org/10.14291/tccon.ggg2014.ascension01.R0/1149285, 2014.

Goo, T.-Y., Oh, Y.-S., and Velazco, V. A.: TCCON data from Anmeyondo (KR), Release GGG2014.R0, TCCON Data Archive, hosted by CaltechDATA, https://doi.org/10.14291/tccon.ggg2014.anmeyondo01.R0/1149284, 2014.

Griffith, D. W. T., Deutscher, N. M., Velazco, V. A., Wennberg, P. O., Yavin, Y., Keppel-Aleks, G., Washenfelder, R., Toon, G. C., Blavier, J.-F., Paton-Walsh, C., Jones, N. B., Kettlewell, G. C., Connor, B., Macatangay, R. C., Roehl, C., Ryczek, M., Glowacki, J., Culgan, T., and Bryant, G.: TCCON data from Darwin (AU), Release GGG2014.R0, TCCON Data Archive, hosted by CaltechDATA, https://doi.org/10.14291/tccon.ggg2014.darwin01.R0/1149290, 2014a.

Griffith, D. W. T., Velazco, V. A., Deutscher, N. M., PatonWalsh, C., Jones, N. B., Wilson, S. R., Macatangay, R. C., Kettlewell, G. C., Buchholz, R. R., and Riggenbach, M.: TCCON data from Wollongong (AU), Release GGG2014.R0, TCCON Data Archive, hosted by CaltechDATA, https://doi.org/10.14291/tccon.ggg2014.wollongong01.R0/1149291, 2014b.

Guerlet, S., Basu, S., Butz, A., Krol, M., Hahne, P., Houweling, S., Hasekamp, O. P., and Aben, I.: Reduced carbon uptake during the 2010 Northern Hemisphere summer from GOSAT, Geophys. Res. Lett., 40, 2378-2383, https://doi.org/10.1002/grl.50402, 2013a.

Guerlet, S., Butz, A., Schepers, D., Basu, S., Hasekamp, O. P., Kuze, A., Yokota, T., Blavier, J.-F., Deutscher, N. M., Griffith, D. W., Hase, F., Kyro, E., Morino, I., Sherlock, V., Sussmann, R., Galli, A., and Aben, I.: Impact of aerosol and thin cirrus on retrieving and validating $X_{\mathrm{CO}_{2}}$ from GOSAT shortwave in- frared measurements, J. Geophys. Res.-Atmos., 118, 4887-4905, https://doi.org/10.1002/jgrd.50332, 2013b.

Gurney, K. R., Law, R. M., Denning, A. S., Rayner, P. J., Baker, D., Bousquet, P., Bruhwiler, L., Chen, Y.-H., Ciais, P., Fan, S., Fung, I. Y., Gloor, M., Heimann, M., Higuchi, K., John, J., Maki, T., Maksyutov, S., Masarie, K., Peylin, P., Prather, M., Pak, B. C., Randerson, J., Sarmiento, J., Taguchi, S., Takahashi, T., and Yuen, C.-W.: Towards robust regional estimates of $\mathrm{CO}_{2}$ sources and sinks using atmospheric transport models, Nature, 415, 626630, 2002.

Hase, F., Blumenstock, T., Dohe, S., Gross, J., and Kiel, M.: TCCON data from Karlsruhe (DE), Release GGG2014.R1, TCCON Data Archive, hosted by CaltechDATA, https://doi.org/10.14291/tccon.ggg2014.karlsruhe01.R1/1182416, 2015.

Hasekamp, O. P. and Butz, A.: Efficient calculation of intensity and polarization spectra in vertically inhomogeneous scattering and absorbing atmospheres, J. Geophys. Res.-Atmos., 113, D20309, https://doi.org/10.1029/2008JD010379, 2008.

Hasekamp, O. P. and Landgraf, J.: A linearized vector radiative transfer model for atmospheric trace gas retrieval, J. Quant. Spectrosc. Ra., 75, 221-238, 2002.

Hasekamp, O. P. and Landgraf, J.: Linearization of vector radiative transfer with respect to aerosol properties and its use in satellite remote sensing, J. Geophys. Res.-Atmos., 110, D04203, https://doi.org/10.1029/2004JD005260, 2005a.

Hasekamp, O. P. and Landgraf, J.: Retrieval of aerosol properties over the ocean from multispectral single-viewing-angle measurements of intensity and polarization: Retrieval approach, information content, and sensitivity study, J. Geophys. Res.-Atmos., 110, D20207, https://doi.org/10.1029/2005JD006212, 2005b.

Hönninger, G., von Friedeburg, C., and Platt, U.: Multi axis differential optical absorption spectroscopy (MAX-DOAS), Atmos. Chem. Phys., 4, 231-254, https://doi.org/10.5194/acp-4231-2004, 2004.

Houweling, S., Breon, F.-M., Aben, I., Rödenbeck, C., Gloor, M., Heimann, M., and Ciais, P.: Inverse modeling of $\mathrm{CO}_{2}$ sources and sinks using satellite data: a synthetic inter-comparison of measurement techniques and their performance as a function of space and time, Atmos. Chem. Phys., 4, 523-538, https://doi.org/10.5194/acp-4-523-2004, 2004.

Houweling, S., Aben, I., Breon, F.-M., Chevallier, F., Deutscher, N., Engelen, R., Gerbig, C., Griffith, D., Hungershoefer, K., Macatangay, R., Marshall, J., Notholt, J., Peters, W., and Serrar, S.: The importance of transport model uncertainties for the estimation of $\mathrm{CO}_{2}$ sources and sinks using satellite measurements, Atmos. Chem. Phys., 10, 9981-9992, https://doi.org/10.5194/acp-10-9981-2010, 2010.

Houweling, S., Krol, M., Bergamaschi, P., Frankenberg, C., Dlugokencky, E. J., Morino, I., Notholt, J., Sherlock, V., Wunch, D., Beck, V., Gerbig, C., Chen, H., Kort, E. A., Röckmann, T., and Aben, I.: A multi-year methane inversion using SCIAMACHY, accounting for systematic errors using TCCON measurements, Atmos. Chem. Phys., 14, 3991-4012, https://doi.org/10.5194/acp-14-3991-2014, 2014.

Iraci, L. T., Podolske, J., Hillyard, P. W., Roehl, C., Wennberg, P. O., Blavier, J.-F., Allen, N., Wunch, D., Osterman, G., and Albertson, R.: TCCON data from Edwards (US), Release GGG2014.R1, TCCON Data Archive, hosted by CaltechDATA, 
https://doi.org/10.14291/tccon.ggg2014.edwards01.R1/1255068, 2016.

Jung, Y., Kim, J., Kim, W., Boesch, H., Lee, H., Cho, C., and Goo, T.-Y.: Impact of aerosol property on the accuracy of a $\mathrm{C}_{2}$ retrieval algorithm from satellite remote sensing, Remote Sens., 8, 322, https://doi.org/10.3390/rs8040322, 2016.

Kawakami, S., Ohyama, H., Arai, K., Okumura, H., Taura, C., Fukamachi, T., and Sakashita, M.: TCCON data from Saga (JP), Release GGG2014.R0, TCCON Data Archive, hosted by CaltechDATA, https://doi.org/10.14291/tccon.ggg2014.saga01.R0/1149283, 2014.

Kivi, R., Heikkinen, P., and Kyrö, E.: TCCON data from Sodankylä (FI), Release GGG2014.R0, TCCON Data Archive, hosted by CaltechDATA, https://doi.org/10.14291/tccon.ggg2014.sodankyla01.R0/1149280, 2014.

Kulawik, S., Wunch, D., O’Dell, C., Frankenberg, C., Reuter, M., Oda, T., Chevallier, F., Sherlock, V., Buchwitz, M., Osterman, G., Miller, C. E., Wennberg, P. O., Griffith, D., Morino, I., Dubey, M. K., Deutscher, N. M., Notholt, J., Hase, F., Warneke, T., Sussmann, R., Robinson, J., Strong, K., Schneider, M., De Mazière, M., Shiomi, K., Feist, D. G., Iraci, L. T., and Wolf, J.: Consistent evaluation of ACOS-GOSAT, BESD-SCIAMACHY, CarbonTracker, and MACC through comparisons to TCCON, Atmos. Meas. Tech., 9, 683-709, https://doi.org/10.5194/amt-9683-2016, 2016.

Lamouroux, J., Tran, H., Laraia, A., Gamache, R., Rothman, L., Gordon, I., and Hartmann, J.-M.: Updated database plus software for line-mixing in $\mathrm{CO}_{2}$ infrared spectra and their test using laboratory spectra in the $1.5-2.3 \mu \mathrm{m}$ region, J. Quant. Spectrosc. Ra., 111, 2321-2331, 2010.

Mandrake, L., O’Dell, C., Wunch, D., Wennberg, P., Fisher, B., Osterman, G., and Eldering, A.: Orbiting Carbon Observatory2 (OCO-2) Warn Level, Bias Correction, and Lite File Product Description, Tech. rep., Jet Propulsion Laboratory, California Institute of Technology, Pasasdena, available at: http://disc.sci.gsfc.nasa.gov/OCO-2/documentation/oco-2-v7/ OCO2_XCO2_Lite_Files_and_Bias_Correction_0915_sm.pdf, last access: 16 October 2015.

Morino, I., Matsuzaki, T., and Horikawa, M.: TCCON data from Tsukuba (JP), 125HR, Release GGG2014.R1, TCCON Data Archive, hosted by CaltechDATA, https://doi.org/10.14291/tccon.ggg2014.tsukuba02.R1/1241486, 2016a.

Morino, I., Yokozeki, N., Matsuzaki, T., and Horikawa, M.: TCCON data from Rikubetsu (JP), Release GGG2014.R1, TCCON Data Archive, hosted by CaltechDATA, https://doi.org/10.14291/tccon.ggg2014.rikubetsu01.R1/1242265, $2016 b$.

Notholt, J., Petri, C., Warneke, T., Deutscher, N. M., Buschmann, M., Weinzierl, C., Macatangay, R. C., and Grupe, P.: TCCON data from Bremen (DE), Release GGG2014.R0, TCCON Data Archive, hosted by CaltechDATA, https://doi.org/10.14291/tccon.ggg2014.bremen01.R0/1149275, 2014.

O’Dell, C. W., Connor, B., Bösch, H., O’Brien, D., Frankenberg, C., Castano, R., Christi, M., Eldering, D., Fisher, B., Gunson, M., McDuffie, J., Miller, C. E., Natraj, V., Oyafuso, F., Polonsky, I.,
Smyth, M., Taylor, T., Toon, G. C., Wennberg, P. O., and Wunch, D.: The ACOS $\mathrm{CO}_{2}$ retrieval algorithm - Part 1: Description and validation against synthetic observations, Atmos. Meas. Tech., 5, 99-121, https://doi.org/10.5194/amt-5-99-2012, 2012.

Patra, P. K., Maksyutov, S., Sasano, Y., Nakajima, H., Inoue, G., and Nakazawa, T.: An evaluation of $\mathrm{CO}_{2}$ observations with Solar Occultation FTS for Inclined-Orbit Satellite sensor for surface source inversion, J. Geophys. Res.-Atmos., 108, 4759, https://doi.org/10.1029/2003JD003661, 2003.

Peters, W., Jacobson, A. R., Sweeney, C., Andrews, A. E., Conway, T. J., Masarie, K., Miller, J. B., Bruhwiler, L. M. P., Pétron, G., Hirsch, A. I., Worthy, D. E. J., van der Werf, G. R., Randerson, J. T., Wennberg, P. O., Krol, M. C., and Tans, P. P.: An atmospheric perspective on North American carbon dioxide exchange: CarbonTracker, P. Natl. Acad. Sci. USA, 104, 1892518930, https://doi.org/10.1073/pnas.0708986104, 2007.

Phillips, D. L.: A technique for the numerical solution of certain integral equations of the first kind, J. ACM, 9, 84-97, 1962.

Prentice, I. C., Farquhar, G., Fasham, M., Goulden, M., Heimann, M., Jaramillo, V., Kheshgi, H., LeQuéré, C., Scholes, R., and Wallace, D. W.: The carbon cycle and atmospheric carbon dioxide, Cambridge University Press, New York, 2001.

Rayner, P. and O'Brien, D.: The utility of remotely sensed $\mathrm{CO}_{2}$ concentration data in surface source inversions, Geophys. Res. Lett., 28, 175-178, 2001.

Reuter, M., Buchwitz, M., Schneising, O., Heymann, J., Bovensmann, H., and Burrows, J. P.: A method for improved SCIAMACHY $\mathrm{CO}_{2}$ retrieval in the presence of optically thin clouds, Atmos. Meas. Tech., 3, 209-232, https://doi.org/10.5194/amt-3209-2010, 2010.

Reuter, M., Bovensmann, H., Buchwitz, M., Burrows, J. P., Connor, B. J., Deutscher, N. M., Griffith, D. W. T., Heymann, J., Keppel-Aleks, G., Messerschmidt, J., Notholt, J., Petri, C., Robinson, J., Schneising, O., Sherlock, V., Velazco, V., Warneke, T., Wennberg, P. O., and Wunch, D.: Retrieval of atmospheric $\mathrm{CO}_{2}$ with enhanced accuracy and precision from SCIAMACHY: Validation with FTS measurements and comparison with model results, J. Geophys. Res.-Atmos., 116, D04301, https://doi.org/10.1029/2010JD015047, 2011.

Rodgers, C. D.: Inverse methods for atmospheric sounding: theory and practice, vol. 2, World Scientific, River Edge, New Jersey, 2000.

Rothman, L., Gordon, I., Barbe, A., Benner, D., Bernath, P., Birk, M., Boudon, V., Brown, L., Campargue, A., Champion, J.-P., Chance, K., Coudert, L., Dana, V., Devi, V., Fally, S., Flaud, J.-M., Gamache, R., Goldman, A., Jacquemart, D., Kleiner, I., Lacome, N., Lafferty, W., Mandin, J.-Y., Massie, S., Mikhailenko, S., Miller, C., Moazzen-Ahmadi, N., Naumenko, O., Nikitin, A., Orphal, J., Perevalov, V., Perrin, A., PredoiCross, A., Rinsland, C., Rotger, M., Šimečková, M., Smith, M., Sung, K., Tashkun, S., Tennyson, J., Toth, R., Vandaele, A., and Auwera, J. V.: The HITRAN 2008 molecular spectroscopic database, J. Quant. Spectrosc. Radiat. T., 110, 533-572, https://doi.org/10.1016/j.jqsrt.2009.02.013, 2009.

Schepers, D., Guerlet, S., Butz, A., Landgraf, J., Frankenberg, C., Hasekamp, O., Blavier, J., Deutscher, N. M., Griffith, D. W. T., Hase, F., Kyro, E., Morino, I., Sherlock, V., Sussmann, R., and Aben, I.: Methane retrievals from Greenhouse Gases Observing Satellite (GOSAT) shortwave infrared mea- 
surements: Performance comparison of proxy and physics retrieval algorithms, J. Geophys. Res.-Atmos., 117, D10307, https://doi.org/10.1029/2012JD017549, 2012.

Schepers, D., aan de Brugh, J., Hahne, P., Butz, A., Hasekamp, O., and Landgraf, J.: LINTRAN v2.0: A linearised vector radiative transfer model for efficient simulation of satellite-born nadir-viewing reflection measurements of cloudy atmospheres, J. Quant. Spectrosc. Ra., 149, 347-359, 2014.

Sherlock, V., Connor, B., Robinson, J., Shiona, H., Smale, D., and Pollard, D.: TCCON data from Lauder (NZ), 125HR, Release GGG2014.R0, TCCON Data Archive, hosted by CaltechDATA, https://doi.org/10.14291/tccon.ggg2014.lauder02.R0/1149298, 2014.

Sussmann, R. and Rettinger, M.: TCCON data from Garmisch (DE), Release GGG2014.R0, TCCON Data Archive, hosted by CaltechDATA, https://doi.org/10.14291/tccon.ggg2014.garmisch01.R0/1149299, 2014.

Te, Y., Jeseck, P., and Janssen, C.: TCCON data from Paris (FR), Release GGG2014.R0, TCCON Data Archive, hosted by CaltechDATA, https://doi.org/10.14291/tccon.ggg2014.paris01.R0/1149279, 2014.

Tikhonov, A. N.: Solution of incorrectly formulated problems and the regularization method, Dokl. Akad. Nauk SSSR+, 151, 501504, 1963.

Tran, H. and Hartmann, J.-M.: An improved $\mathrm{O}_{2}$ A band absorption model and its consequences for retrievals of photon paths and surface pressures, J. Geophys. Res.-Atmos., 113, D18104, https://doi.org/10.1029/2008JD010011, 2008.

Warneke, T., Messerschmidt, J., Notholt, J., Weinzierl, C., Deutscher, N. M., Petri, C., Grupe, P., Vuillemin, C., Truong, F., Schmidt, M., Ramonet, M., and Parmentier, E.: TCCON data from Orléans (FR), Release GGG2014.R0, TCCON Data Archive, hosted by CaltechDATA, https://doi.org/10.14291/tccon.ggg2014.orleans01.R0/1149276, 2014.

Wennberg, P. O., Roehl, C., Wunch, D., Toon, G. C., Blavier, J.-F., Washenfelder, R., Keppel-Aleks, G., Allen, N., and Ayers, J.: TCCON data from Park Falls (US), Release GGG2014.R0, TCCON Data Archive, hosted by CaltechDATA, https://doi.org/10.14291/tccon.ggg2014.parkfalls01.R0/1149161, 2014

Wennberg, P. O., Wunch, D., Roehl, C., Blavier, J.-F., Toon, G. C., and Allen, N.: TCCON data from Lamont (US), Release GGG2014.R1, TCCON Data Archive, hosted by CaltechDATA, https://doi.org/10.14291/tccon.ggg2014.lamont01.R1/1255070, 2016.
Wunch, D., Toon, G. C., Blavier, J.-F. L., Washenfelder, R. A., Notholt, J., Connor, B. J., Griffith, D. W., Sherlock, V., and Wennberg, P. O.: The total carbon column observing network, Philos. T. Roy. Soc. A, 369, 2087-2112, 2011a.

Wunch, D., Wennberg, P. O., Toon, G. C., Connor, B. J., Fisher, B., Osterman, G. B., Frankenberg, C., Mandrake, L., O'Dell, C., Ahonen, P., Biraud, S. C., Castano, R., Cressie, N., Crisp, D., Deutscher, N. M., Eldering, A., Fisher, M. L., Griffith, D. W. T., Gunson, M., Heikkinen, P., Keppel-Aleks, G., Kyrö, E., Lindenmaier, R., Macatangay, R., Mendonca, J., Messerschmidt, J., Miller, C. E., Morino, I., Notholt, J., Oyafuso, F A., Rettinger, M., Robinson, J., Roehl, C. M., Salawitch, R. J., Sherlock, V., Strong, K., Sussmann, R., Tanaka, T., Thompson, D. R., Uchino, O., Warneke, T., and Wofsy, S. C.: A method for evaluating bias in global measurements of $\mathrm{CO}_{2}$ total columns from space, Atmos. Chem. Phys., 11, 12317-12337, https://doi.org/10.5194/acp-11-12317-2011, 2011 b.

Wunch, D., Toon, G. C., Sherlock, V., Deutscher, N. M., Liu, C., Feist, D. G., and Wennberg, P. O.: The Total Carbon Column Observing Network's GGG2014 Data Version, Carbon Dioxide Information Analysis Center, Oak Ridge National Laboratory, Oak Ridge, Tennessee, USA, available at: https://data.caltech. edu/records/249, 2015.

Wunch, D., Wennberg, P. O., Osterman, G., Fisher, B., Naylor, B., Roehl, C. M., O’Dell, C., Mandrake, L., Viatte, C., Kiel, M., Griffith, D. W. T., Deutscher, N. M., Velazco, V. A., Notholt, J., Warneke, T., Petri, C., De Maziere, M., Sha, M. K., Sussmann, R., Rettinger, M., Pollard, D., Robinson, J., Morino, I., Uchino, O., Hase, F., Blumenstock, T., Feist, D. G., Arnold, S. G., Strong, K., Mendonca, J., Kivi, R., Heikkinen, P., Iraci, L., Podolske, J., Hillyard, P. W., Kawakami, S., Dubey, M. K., Parker, H. A., Sepulveda, E., García, O. E., Te, Y., Jeseck, P., Gunson, M. R., Crisp, D., and Eldering, A.: Comparisons of the Orbiting Carbon Observatory-2 (OCO-2) $X_{\mathrm{CO}_{2}}$ measurements with TCCON, Atmos. Meas. Tech., 10, 2209-2238, https://doi.org/10.5194/amt10-2209-2017, 2017.

Yokota, T., Yoshida, Y., Eguchi, N., Ota, Y., Tanaka, T., Watanabe, H., and Maksyutov, S.: Global concentrations of $\mathrm{CO}_{2}$ and $\mathrm{CH}_{4}$ retrieved from GOSAT: First preliminary results, Sola, 5, 160163, 2009.

Yoshida, Y., Ota, Y., Eguchi, N., Kikuchi, N., Nobuta, K., Tran, H., Morino, I., and Yokota, T.: Retrieval algorithm for $\mathrm{CO}_{2}$ and $\mathrm{CH}_{4}$ column abundances from short-wavelength infrared spectral observations by the Greenhouse gases observing satellite, Atmos. Meas. Tech., 4, 717-734, https://doi.org/10.5194/amt-4717-2011, 2011. 